\title{
The Impact of Tail Risk on Stock Market Returns: The Role of Market Sentiment
}

\author{
Thanaset Chevapatrakul* Zhongxiang $\mathrm{Xu}^{\dagger} \quad \mathrm{Kai} \mathrm{Yao}^{\ddagger}$
}

August 2018

\begin{abstract}
We examine the return predictability of time-varying extreme-event risk at the different points on the return distribution using quantile regression. We find evidence of strong predictive power at the lower quantiles for forecast horizons of up to one year. At the higher quantiles, however, our results show no association between tail risk and the excess stock market returns. Taken together, the evidence explains the abnormally large equity premium, observed during periods of sharp falls in stock prices when market sentiment is bearish.
\end{abstract}

JEL classification: C21; C51; C53; G12; G17

Keywords: Quantile regression; stock markets; return predictability; asymmetry

\footnotetext{
*Corresponding author. Nottingham University Business School, Jubilee Campus, Wollaton Road, Nottingham, NG8 1BB. Email: Thanaset.Chevapatrakul@nottingham.ac.uk. Tel: +44 (0) 1158232490.

${ }^{\dagger}$ Tsinghua University, PBC School of Finance, 43 Chengfu Road, Beijing 100083, P.R. China; E-mail: xuzhx@pbcsf.tsinghua.edu.cn.

${ }^{\ddagger}$ China Center for Behavioral Economics and Finance, Southwestern University of Finance and Economics, 555 Liutai Avenue, Chengdu 611130, China. Email: yykk.yao@gmail.com.
} 


\section{Introduction}

Research on the potential impact of rare events has attracted considerable attention not least because several puzzling phenomena in financial markets can be explained by incorporating probability of extreme events in the analysis. Dating back by almost three decades, Rietz (1988) develops an asset pricing model that can capture the effect of low-probability market crashes. The author argues that, given reasonable degrees of time preference and risk aversion, the extreme event risk helps solve the equity risk premium puzzle discussed in Mehra and Prescott (1985). Barro (2006) also demonstrates that high equity premium, the low risk-free rate, and volatile stock returns, commonly observed in financial markets, can be explained when historical data is calibrated with disaster probabilities.

Several researchers subsequently extend the model of Rietz (1988) and Barro (2006) by allowing the left tail risk premium to vary over time. Among literature in this strand is Gabaix (2012) who incorporates a time-varying intensity of disasters in the Rietz-Barro type model. His extended model provides an explanation for the time-varying risk premium which gives rise to asset price volatility and return predictability. Built upon Rietz (1988), Barro (2006) and Gabaix (2012), Gourio (2012) introduces a time-varying risk of a large macroeconomic shock in a real business cycle model. The resulting model is found to fit the data well and can account for the fall in stock prices, employment, output and investment during a "disaster", such as the Great Depression. Subsequently, Wachter (2013) includes a time-varying probability of a consumption disaster, whose intensity of jumps is specified as a square-root process à la Cox et al. (1985), in the model. Her findings demonstrate that the time-varying disaster risk helps explain many features of the financial markets: the time-varying equity risk premium and the lower risk-free rate.

More recently, Kelly and Jiang (2014) develop a time-varying measure of tail risk, extracted from the cross section of individual stocks. The measure is shown to possess strong predictive power for the excess stock market returns and is capable of forecasting annualised excess market returns at the one-month, one-year, three-year and five-year investment horizons. Moreover, the degree of portfolio's exposure to tail risk is also found to predict the cross section of stock returns. The authors report that stocks in the highest quintile portfolio, sorted based on the degree of portfolio's exposure to the tail risk measure, earn annualised value-weighted three-factor alphas of $5.5 \%$ higher than stocks in the lowest quintile portfolio.

Motivated by the asset pricing implication of tail risk, we extend the work of Kelly and Jiang (2014) one step further. Because the ordinary least square (OLS) method is employed in their analysis, the impact of tail risk on returns is computed when the return is located at the mean of the return distribution. This finding, though informative, only describes the relation during "normal" times; it says nothing about the relation when the return is far from the mean. Since tail risk is predominantly associated with extreme negative events, it is plausible that financial markets' reaction to tail risk is asymmetric, depending on where the return is located on the return distribution. In other words, the impact of tail risk on stock returns is expected to vary 
depending on whether the market sentiment is bullish (i.e., when the excess return is highly positive) or bearish (i.e., when the excess return is highly negative). This is the focus of our paper.

Literature on the asymmetric response of financial markets to shocks is abundant. Examining the impact of news on return volatility, Nelson (1991) and Glosten et al. (1993), for example, show that markets react more aggressively to bad news than good news. Furthermore, Chevapatrakul (2014) and Chevapatrakul (2015) both reveal that stock markets respond asymmetrically to changes in monetary policy depending on the level of the stock market return. Investigating the causality between past trading volume and index returns in the Pacific Basin countries, Gebka and Wohar (2013) uncover strong nonlinear causality. They find that the volume-return relationship is positive when returns are high and negative when returns are low. Wu and Lee (2015) show that the intertemporal risk-return relationship in the US is significantly positive (negative) in bull (bear) markets. From a behavioural perspective, markets' reaction to investor's sentiment, however, is ambiguous. As explained in Lee et al. (2002), on the one hand, when sentiment is overall bullish (bearish), trading activities cause a purchase (sale) price to rise (fall) above (below) the fundamental value, thereby lowering the expected return. On the other hand, as demand for the risky assets increases (decreases) following more positive (negative) sentiment, the overall level of market risk increases (decreases), leading to higher (lower) expected returns.

To measure the asymmetric response of stock markets to tail risk, this paper employs the quantile regression technique, pioneered by Koenker and Bassett (1978), to examine the effect of tail risk on the excess market returns at the different points on the return distribution. The approach allows comparison of the impact of tail risk on the excess stock market returns across the different quantiles of the return distributions. Specifically, we test the hypothesis that financial markets' reaction to tail risk during "bad" times (i.e., when returns are negative and located at the lower quantiles) differs from the reaction during "good" times (i.e., when returns are positive and located at the upper quantiles). Our choice of methodology is motivated by empirical evidence based on the quantile regression technique which suggests that return predictability varies depending on where the return is located on the return distribution and that modelling risk and returns using quantile regression yields significant improvement over the conditional mean methods. For instance, Baur et al. (2012) report that positive returns exhibit negative dependence on past returns while negative returns are marked by positive dependence, suggesting that investors overreact (underreact) to macroeconomic news in good (bad) states. Employing both the OLS and the quantile regression techniques to test the idiosyncratic riskreturn relationship using the Australian data, Nath and Brooks (2015) find that the relationship is negative and statistically significant only when the models are estimated at the mean using quantile regression.

As a preview of our main results, we find that an increase in tail risk predicts a near-term rise in the excess stock market returns when the return is located at the mean and the lower quantiles. The relation between the time-varying tail risk and returns is positive and statistically 
significant. At the lower quantiles, our evidence suggests that markets respond more forcefully with a rise in the excess stock market return of approximately $20 \%$ per annum following a one-standard-deviation increase in the time-varying tail risk measure. At the upper quantiles of the return distribution, however, markets' reaction to tail risk is not detected. We also find that the return predictability of tail risk disappears beyond the one-year forecast horizon.

This paper contributes to the existing research in two ways. Firstly, consistent with both theoretical and empirical literature, our results confirm the significant impact of tail risk on stock returns. The explanatory power of tail risk is, however, evident only at the extreme left tail of the return distribution. The results imply that when stock prices fall sharply, the risk premium demanded by market participants to compensate for tolerating the lower tail risk rises, exacerbating further falls in prices. This may explain the contagious nature of systemic risk and the speed at which a liquidity crisis can spread across different segments of the financial markets. Secondly, the empirical evidence suggests that, during times of rising stock prices, traders and investors appear to discount the possibility of extreme-event risk as our results show that the impact of tail risk on stock returns disappears at the upper quantiles. The evidence points to financial markets' underreaction to extreme negative shocks in good states. This may be the reason why financial markets become complacent when sentiment is bullish.

This paper is organised in the following manner. We discuss the calculation of tail risk and the quantile regression in the next section. Section 3 provides details of our dataset. The empirical analysis and the main findings are discussed in Section 4. Section 5 investigates the robustness of our results. Finally, Section 6 concludes the paper.

\section{Methodology}

\subsection{Measuring Tail Risk}

The main obstacle to estimating extreme-event risk accurately is data limitation. Because tail events rarely occur, quantifying tail risk from a univariate time series poses a serious challenge. Kelly and Jiang (2014) propose a method which can be used to capture common variation in the rare-event risk from a large pool of securities based on the idea that firm-level tail distributions are driven by similar dynamics. Their technique has two advantages over the option-based approach, discussed in Bakshi et al. (2003), and the high-frequency approach, explained in Bollerslev and Todorov (2011), because it can be straightforwardly applied to low frequency data and is not subject to the data limitation issue as sample horizons for both option and high-frequency data are currently only around 20 years.

Following Kelly and Jiang (2014), we define the lower tail distribution during month $t$ as a set of asset returns which fall below a pre-defined tail threshold value, $u_{t}$, which denotes a suitably extreme quantile below which any returns are assumed to obey a power law:

$$
P\left(R_{i, t+1}<r \mid R_{i, t+1}<u_{t} \text { and } \Omega_{t}\right)=\left(\frac{r}{u_{t}}\right)^{-a_{i} / \lambda_{t}}
$$


where $r<u_{t}<0, u_{t}$ is the extreme negative threshold value in month $t, a_{i} / \lambda_{t}$ is the tail exponent determining the shape of the tail, and $\Omega_{t}$ is the information set available to the investor in month $t .{ }^{1}$ Because $r / u_{t}>1, a_{i} / \lambda_{t}>0$ which ensures that $\left(r / u_{t}\right)^{-a_{i} / \lambda_{t}}>0$. Importantly, while $a_{i}$ in Eq. (1) measures the level of tail risk for individual assets, in a sufficiently large cross section of assets, the dynamics for all the assets are assumed to be driven by a time-varying common process: tail risk, denoted by $\lambda_{t}$. It is worth noting that high values of $\lambda_{t}$ correspond to distributions with fat tails, implying high probabilities of extreme returns.

The power law estimator, discussed in Hill (1975), employs only observations which exceeds the threshold (i.e., exceedences) in the calculation. Because nonexceedences are not in the tail domain, they need not obey the power law and therefore can be omitted from the calculation of the tail risk measure. By pooling all the daily stock returns within the month, the tail risk measure for month $t$ is calculated as follows:

$$
\lambda_{t}=\frac{1}{K_{t}} \sum_{k=1}^{K_{t}} \ln \frac{R_{k, t}}{u_{t}}
$$

where $R_{k, t}$ is the value of the stock return observation which exceeds the tail threshold on day $k$ during month $t$ and $K_{t}$ is the total number of daily stock return observations exceeding the threshold during month $t$. Because $R_{k, t}<u_{t}$, therefore $R_{k, t} / u_{t}>1$.

As explained in Kelly and Jiang (2014), return observations whose values are below threshold $u_{t}$ obey a power law with exponent $a_{i} / \lambda_{t}$; their logarithmic values are exponentially distributed with scale parameter $a_{i} / \lambda_{t}$. When all stocks have the same ex ante probability of falling below $u_{t}$, the expected value of $\lambda_{t}$ turns out to be the cross-sectional harmonic average tail exponent which can be expressed by the following equation:

$$
\mathrm{E}_{t-1}\left[\frac{1}{K_{t}} \sum_{k=1}^{K_{t}} \ln \frac{R_{k, t}}{u_{t}} \mid \lambda_{t}, R_{k, t}<u_{t}\right]=\lambda_{t} \frac{1}{\bar{a}}
$$

where

$$
\frac{1}{\bar{a}} \equiv \frac{1}{n} \sum_{i=1}^{n} \frac{1}{a_{i}} .
$$

Eq. (3) states that the estimator of Hill (1975) equals the common tail risk component, $\lambda_{t}$, times a constant multiplicative bias term $1 / \bar{a}$, indicating that the Hill's estimator is perfectly correlated with the tail risk dynamic, $\lambda_{t}$.

\subsection{Quantile Regression}

In its early days, the method of quantile regression, pioneered by Koenker and Bassett (1978), has been employed predominantly by applied microeconometricians. Its popularity, however, has increased markedly during the past decades, thanks to a rapidly expanding empirical quantile regression literature in economics which makes a persuasive case for the value of "going beyond

\footnotetext{
${ }^{1}$ For an accessible introduction to the power law, see Gabaix (2016).
} 
models for the conditional mean" (Koenker and Hallock, 2001). The method is now widely adopted by researchers in different research areas in economics and finance because it provides a broader and clearer picture of the relationship between the dependent variable and the covariates, resulting in a more informative empirical analysis.

In the traditional conditional mean model, the error term is assumed to have identical distribution. Koenker and Hallock (2001) refer to this type of models as a pure location shift model. If the error term behaves as assumed, then only the location, not the scale, of the dependent variable is affected by variation in the explanatory variables. Since shocks to financial markets are often found to be heteroskedastic, models of asset prices with the pure location shift feature are not quite appropriate. Due to the semiparametric nature of quantile regression, researchers do not need to make an explicit assumption regarding the distribution of the error term (e.g., Gaussian). Quantile regression estimators are still consistent even if the assumption of the distribution of the error term is violated. Furthermore, in the same way that the median is more robust to outliers than the mean, quantile regression estimators are also shown to be more robust to the presence of outliers in the data than the OLS estimators.

We measure the impact of time-varying tail risk on the excess stock market returns by estimating the following conditional quantile model:

$$
q_{\tau}\left(R_{m, t} \mid \tilde{\lambda}_{t-h}\right)=\alpha_{\tau}+\beta_{\tau} \tilde{\lambda}_{t-h}
$$

where $q_{\tau}(\bullet)$ is the conditional quantile function and $\tau=0.05,0.10,0.20, \ldots, 0.90,0.95 . R_{m, t}$ is the monthly excess market return realised in month $t$ and $\tilde{\lambda}_{t-h}$ is the standardised tail risk measure with zero mean and unit variance observed in month $t-h$ where $h$ is the forecast horizon. We use the standardised tail risk measure, $\tilde{\lambda}$, in Eq. (5) so that the regression coefficient can be conveniently interpreted as the estimated change in the $h$-month ahead excess stock market return following a one-standard-deviation change in tail risk. In this paper, we are particularly interested in $h=1,3,12,36,60$ : one-month, three-month, one-year, three-year and five-year ahead forecast horizons.

To compute the estimate of the impact of tail risk on the $h$-month ahead excess stock market return at the $\tau$ th quantile, $\beta_{\tau}$, we solve the following minimisation problem:

$$
\min _{\beta_{\tau}} \sum_{t=1}^{T} \rho_{\tau}\left(R_{m, t}-\alpha_{\tau}-\beta_{\tau} \tilde{\lambda}_{t-h}\right)
$$

where $\rho_{\tau}(z)=z\left(\tau-\mathbf{1}_{[z \leq 0]}\right)$. The check function $\mathbf{1}_{[z \leq 0]}=1$ if $z \leq 0$ and 0 otherwise. The function $\rho_{\tau}(z)$ introduces different weights on the residuals in the minimisation problem in Eq. (6). When $\tau=0.95$, for example, positive residuals receive a weight of $95 \%$ while negative residuals are given a weight of $5 \%$. When the value of $\tau$ equals 0.5 , we obtain the median estimator as the solution. 


\section{Data}

To calculate the monthly time series of tail risk, $\lambda_{t}$, in Eq. (2), we use daily data for all stocks listed on the NYSE, AMEX, and NASDAQ between January 1973 and December 2015. The data are obtained from the Centre for Research in Security Prices (CRSP) database. Our empirical analysis is performed on monthly time series because the tail risk measure for each month is computed from daily return observations. We therefore require a sufficiently large number of data points in the calculation to ensure reliability of our results. Returns on delisted stocks are adjusted following a widely used approach, discussed in Shumway (1997). ${ }^{2}$ The number of observations for non-missing returns in our sample after adjusting for delisted returns is $56,411,980$. For each month, the average and the minimum numbers of non-missing return observations are 111,929 and 69,523 respectively.

We compute the tail risk estimate for each month using only observations of stocks within the month whose daily returns fall below the tail threshold, $u_{t}$, specified to be the 5 th quantile of the return distribution. ${ }^{3}$ The descriptive statistics for the tail risk measure are reported in Table 1. Based on the mean and the standard deviation statistics, $95 \%$ of the tail risk values lie between 0.35 and 0.53 . The distribution is left-skewed and has slightly thin tails. For each month, the average number of stocks (observations) used in the calculation of tail risk is 2,423 $(5,647)$ while the number of stocks (observations) exceeding the threshold varies between 1,511 $(3,477)$ and $4,150(8,562)$. All the threshold values are negative with the average value of $-5.4 \%$.

The estimated $\operatorname{AR}(1)$ parameter for the tail risk measure is 0.712 and is statistically significant at the $1 \%$ significance level, pointing to a high degree of persistence in time-varying tail risk. Our estimate of the $\mathrm{AR}(1)$ parameter differs somewhat from the estimated value of 0.927 reported in Kelly and Jiang (2014). A possible reason may be that the sample used in our calculation differs from their sample. ${ }^{4}$ In addition, Kelly and Jiang (2014) report that the correlation between the upper tail risk and the lower tail risk is $81 \%$, indicating that the estimated tail risk dynamics are highly symmetric. Consistent with their finding, the upper tail risk and the lower tail risk in our sample are also found to be highly correlated with a correlation coefficient of $78 \%$.

To ensure that our results are robust to the choice of the dependent variable, we examine the impact of time-varying tail risk on excess market returns of two stock market indices: the CRSP value-weighted index and the S\&P 500 index. The risk-free rate used in the calculation of the excess market returns is the yield on the one-month U.S. Treasury bills. The time series of the CRSP value-weighted excess returns and the risk-free rate are downloaded from the data library on Kenneth French's website. ${ }^{5}$ The S\&P 500 index data are obtained from the CRSP

\footnotetext{
${ }^{2}$ Specifically, if the value of a delisted return is available in the CRSP database, it is assigned to the missing return. If the value is not available, the value of $-30 \%$ is assigned to the missing return if the value in the DLSTCD field equals one of the following: $500,520,551, \ldots, 574,580$ or 584 . Otherwise, the missing return is assigned the value of $-100 \%$.

${ }^{3}$ Kelly and Jiang (2014) report that their results are not sensitive to the choice of threshold values lying between the 1 th and the 5 th quantiles.

${ }^{4}$ Their sample starts from January 1963 and ends in December 2010.

${ }^{5}$ http://mba.tuck.dartmouth.edu/pages/faculty/ken.french/data_library.html
} 
database. We can report that, on average, the tail risk measure for each month is calculated from $5.0 \%$ and $1.2 \%$ of the return observations in the CRSP value-weighted index and the S\&P 500 index, respectively. Furthermore, approximately $17.0 \%$ of the constituents of the S\&P 500 index are used in the calculation of the tail risk measure for each month.

According to the statistics reported in Table 1, the mean monthly excess returns of the CRSP value-weighted index and the S\&P 500 index are 0.005 and 0.007 with standard deviations of 0.046 and 0.044 , respectively. The distributions of both return series exhibit negative skewness and positive excess kurtosis, suggesting that they are not normally distributed. According to the results from the normality tests, proposed by D'Agostino (1970) and Jarque and Bera (1987), we can comfortably reject the null hypotheses of normality at the $1 \%$ significance level for both return series. Moreover, the return observations below the 40th quantile are all negative.

Time series plots of the tail risk measure and the one-year ahead excess returns on the CRSP value-weighted index and the S\&P 500 index are shown in Figures 1a and 1b, respectively. At first glance, we can see from both plots that, to a certain degree, the one-year ahead excess returns and the tail risk measure move in tandem, loosely tracking each other. However, closer inspection reveals the tendency for the relationship to become stronger when returns move into the negative territory. This is to be expected as there is little amount of extreme-event risk in the markets during periods of bullish sentiment when returns are positive.

\section{Empirical Analysis}

\subsection{Model Specification Tests}

The first step in our analysis involves performing a nonparametric heteroskedasticity-consistent model specification test, proposed by Racine (2006), to examine if the conditional quantile function in Eq. (5) is correctly specified. ${ }^{6}$ As emphasised in Racine (2006), model specification tests are necessary when estimating a conditional quantile function because a model that is correctly specified at the median may not necessary be correctly specified at other quantiles, and vice versa. This is in contrast to the conditional mean model. A consequence of model misspecification is that statistical inference based on the conventional variance-covariance matrix will be invalid. Racine (2006) recommends testing for correct specification of parametric quantile regression models for each quantile at which the model is estimated. We therefore apply the procedure to Eq. (5), setting $\tau=0.05,0.10,0.20, \ldots, 0.90,0.95$ and $h=1,3,12,36,60$.

The test results reported in Table 2 suggest that, for the most part, we cannot reject the null hypothesis of correct specification at most of the quantiles under examination. The test statistics indicate that the model is correctly specified at the lower quantiles, except at $\tau=0.10$ and $h=12$ for the CRSP value-weighted index, where we reject the null hypothesis at the $10 \%$ significance level, and at $\tau=0.10$ and $h=60$ for the S\&P 500 index, where we reject the null hypothesis at the $5 \%$ significance level.

\footnotetext{
${ }^{6}$ The nonparametric heteroskedasticity-consistent model specification tests are performed in $\mathrm{R}$ using package np developed by Jeffrey Racine. The package is downloaded from https://cran.r-project.org/package=np.
} 


\subsection{Model Estimations \& Results}

We estimate the specification in Eq. (5), setting $\tau=0.05,0.10, \ldots, 0.90,0.95$ and $h=$ $1,3,12,36,60$, for both the CRSP value-weighted index and the S\&P 500 index. Since the model is found to be misspecified at some quantiles, standard errors of $\hat{\beta}_{\tau}$ are bootstrapped following the procedure discussed in Buchinsky (1995) to ensure correct statistical inference. The values of the estimated quantile regression slope parameter $\hat{\beta}_{\tau}$ are reported in Table 3 . For comparison, we also report the values of the estimated OLS slope coefficient, denoted by $\hat{\beta}_{\text {OLS }}$, and their bootstrapped standard errors.

The OLS regression results reported in Table 3 uncover a number of interesting findings. The estimated value of $\beta_{\text {OLS }}$ is statistically significant at the conventional levels when $h=1$ for the CRSP value-weighted index and when $h=1$ and 12 for the S\&P 500 index. At the one-month horizon, the estimated coefficient value of 0.004 for both the stock market indices implies that a one-standard-deviation increase in the tail risk measure is associated with an increase in the excess return of $0.4 \%$ per month or $4.8 \%$ per annum. This value is comparable to the value of $4.5 \%$ reported in Kelly and Jiang (2014). Our results, however, point to a lack of return predictability of time-varying tail risk beyond the one-year forecast horizon because the estimated value of $\beta_{\text {OLS }}$ is not statistically significant when $h=36,60$.

Turning attention to the quantile regression results, the statistics in Table 3 indicate the following. Firstly, consistent with the OLS results, extreme-event risk is found to predict the excess market returns for up to the one-year forecast horizon. More importantly, the impact of tail risk on the one-year ahead excess stock market returns on both the CRSP value-weighted index and the S\&P 500 index is strongest at the extreme lower quantiles of the return distributions. For instance, the estimated values of $\beta_{0.05}$ when $h=1$ equal 0.017 and 0.016 for the CRSP value-weighted index and the $\mathrm{S} \& \mathrm{P} 500$ index, respectively. These values suggest that a onestandard-deviation increase in tail risk causes an increase of $1.7 \%$ per month (20.4\% per annum) in the one-month ahead excess market return on the CRSP value-weighted index and an increase of $1.6 \%$ per month (19.2\% per annum) in the one-month ahead excess market return on the S\&P 500 index. These figures are much larger than the response at the mean returns of $0.4 \%$ per month (4.8\% per annum) reported earlier. At the horizons of up to one year (i.e,. when $h=1,3,12$ ), the impact of tail risk on the excess stock market returns dissipates gradually as we move from the left tails towards the right tails of the return distributions. Beyond the median, the impact of tail risk on the excess market returns completely disappears as the estimated coefficient $\hat{\beta}_{\tau}$ is no longer statistically significant.

Taken together, the quantile regression results suggest that the return predictability of tail risk originates from the lower quantiles. They show that an increase in tail risk induces a near-term rise in the excess market returns during "bad" months, when the returns are negative, while the effect of tail risk on the market excess returns disappear altogether during "good" months when the returns are positive. Our results corroborate with the empirical evidence discussed in Lettau and Ludvigson (2003) who show that the expected equity risk premium 
rises during periods of high volatility which, as pointed out by Lee et al. (2002), occur precisely during bad times when sentiment is bearish. During periods of rising stock prices when positive returns are observed, however, the relation is found to be weak as market sentiment is bullish and the likelihood of crash is small.

Figure 2 plots estimates of the quantile regression process for the estimated impact $\hat{\beta}_{\tau}$ for both the excess market returns for $\tau=0.05,0.08,0.11, \ldots, 0.95$ and $h=1,3,12,36,60$ along with the $90 \%$ confidence intervals, depicted by the grey shades. As can be seen from Figures $2 \mathrm{a}-2 \mathrm{f}$, the quantile regression estimates for forecast horizons of up to one year (i.e., $h=1,3,12$ ) are positive and statistically significant between the 5th and the 30th quantiles as the lower bounds of the confidence intervals lie above zero. The estimated coefficient values decline monotonically as we move towards the right tails of the distributions. Beyond the 40th quantiles, the confidence intervals include the value of zero, pointing to the absence of the effect of time-varying tail risk on the excess market returns. For comparison, Figures $2 \mathrm{~g}-2 \mathrm{j}$ show the quantile regression processes for $\hat{\beta}_{\tau}$ and the confidence intervals for forecast horizons of 3 and 5 years (i.e., when $h=36,60)$. The plots show the muted reaction of the excess market returns to tail risk across all the quantiles.

\subsection{Slope Equality Tests}

We further conduct the slope equality test, proposed by Koenker and Bassett (1982), to test the following null hypotheses: $\beta_{0.05}=\beta_{0.95}$ and $\beta_{0.25}=\beta_{0.75}$. The procedure is carried out to ensure that the estimated relation between the excess stock market return and tail risk does not just follow the location shift hypothesis whereby the estimated relationship is constant for all the conditional quantile functions.

The tests are performed on both the excess returns on the CRSP value-weighted index and the S\&P 500 index for $h=1,3,12,36,60$. We report the test statistics and their bootstrapped standard errors in Table 4. The test results indicate that the difference between the values of $\beta_{0.05}$ and $\beta_{0.95}$ is statistically significant at the conventional levels for both indices for $h=1,3,12$. The difference between $\beta_{0.25}$ and $\beta_{0.75}$ is also statistically significant but only when $h=1,3$.

\section{Robustness of Results}

In this section, we examine the predictive performance of the tail risk measure after controlling for the impact of variables that have previously been suggested by the academic literature to be good predictors of the equity premium (Goyal and Welch, 2008). Specifically, we estimate a bivariate quantile function of the following form:

$$
q_{\tau}\left(R_{m, t} \mid \tilde{\lambda}_{t-h}, \tilde{x}_{t-h}\right)=\alpha_{\tau}+\beta_{\tau} \tilde{\lambda}_{t-h}+\gamma_{\tau} \tilde{x}_{t-h}
$$

where $\tilde{x}_{t-h}$ denotes the standardised value at time $t-h$ of an additional regressor in the set of alternative predictors: the book-to-market ratio $(\mathrm{B} / \mathrm{M})$, the Treasury-bill rate (TB), the 
long-term yield (LTY), the net equity expansion (NEE), the rate of inflation (INF), the long-term rate of returns (LTR), the stock return variance (SV), the default yield spread (DYS), the dividend price ratio $(\mathrm{D} / \mathrm{P})$, the dividend payout ratio $(\mathrm{D} / \mathrm{E})$, the earnings price ratio $(\mathrm{E} / \mathrm{P})$ and the term spread (TS). ${ }^{7}$ Similar to the sample period used in the calculation of the tail risk measure, the sample of the alternative predictors starts from January 1973 to December 2015. Descriptive statistics of the alternative predictors are provided in Table 5.

Similar to the estimation of our main specification in Eq. (5), we estimate Eq. (7) for both the CRSP value-weighted index and the S\&P 500 index returns, setting $\tau=0.05,0.10, \ldots, 0.90,0.95$ and $h=1,3,12,36,60$. A total of twelve bivariate models are estimated - one for each of the alternative predictors. For comparison purposes, Eq. (7) is also estimated using OLS. In the interest of brevity, we report only the OLS and the quantile regression results for the one-month forecast horizon (i.e., $h=1$ ) at $\tau=0.05,0.30,0.50,0.80$, and 0.95 . The results for the CRSP value-weighted index returns are reported in Table 6 while the results for the S\&P 500 index returns are reported in Table 7 . In each table, columns $3-7$ show the quantile regression estimates of the coefficient on the tail risk measure, $\hat{\beta}_{\tau}$, for $\tau=0.05,0.30,0.5,0.80$, and 0.95 . Columns 2 and 8 show the estimated OLS coefficient on tail risk, $\hat{\beta}_{\mathrm{OLS}}$, and the estimated OLS coefficient on the alternative predictor, $\hat{\gamma}_{\text {OLS }}$, respectively. All the standard errors are bootstrapped following Buchinsky (1995).

According to the statistics presented in Tables 6 and 7, it can be seen that after controlling for the effect of each of the alternative predictors on the excess stock market returns, the explanatory power of tail risk remains strong at the means as well as at the lower quantiles of the return distributions. Consistent with the results reported earlier in Section 4.2 , both $\hat{\beta}_{0.05}$ and $\hat{\beta}_{0.30}$ are statistically significant at the conventional levels. The only exception is when the stock variance (SV) is included in the bivariate model as an additional predictor of the S\&P 500 index return in which case the estimated parameter of tail risk becomes insignificant. It is worth noting, however, that the predictive power of tail risk in the bivariate setting does not diminish even when the estimated slope parameters on the Treasury-bill rate (TB) and the long-term rate (LTR) are both statistically significant. The results suggest that the tail risk measure contains predictive information beyond that of the Trasury-bill rate and the long-term rate. ${ }^{8}$

Accompanying our quantile regression results reported in Tables 6 and 7 are plots of the quantile process estimates of the tail risk parameter, $\hat{\beta}_{\tau}$. They are presented in Figures 3 and 4 , respectively. Each plot illustrates the estimated reaction of the stock market excess return to tail risk at different quantiles along the return distribution after controlling for the impact of the

\footnotetext{
${ }^{7}$ For information on the variables, their calculation and data sources see Goyal and Welch (2008).

${ }^{8}$ We also estimate an alternative specification:

$$
q_{\tau}\left(R_{m, t} \mid \tilde{\lambda}_{t-h}, \tilde{x}_{t}\right)=\alpha_{\tau}+\beta_{\tau} \tilde{\lambda}_{t-h}+\gamma_{\tau} \tilde{x}_{t}
$$

where the contemporaneous value of the alternative predictor, $x_{t}$, is employed as an additional explanatory variable regardless of the forecast horizon. The results are robust: the standardised tail risk measure can explain variation in the one-month ahead excess stock market returns. Results for forecast horizons beyond one month (i.e., $h=3,12,36$ and 60 ) for Eq. (7) suggest that none of the variables in the bivariate model possesses return predictability. These results are not reported in the paper but are available from the authors upon request.
} 
alternative predictor. In general, all the plots show a similar pattern of monotonically declining effect of tail risk on the excess market returns as we move along the return distributions from the lower quantiles to the upper quantiles. The relation between tail risk and the excess market returns is statistically significant only when the return is below the median.

Our bivariate regression results indicate that the predictability of tail risk coming from the lower part of the return distribution remains robust even after controlling for the explanatory power of the alternative return predictors surveyed in Goyal and Welch (2008). The results of the robustness tests, which are consistent with our main results reported in Section 4.2, confirm the stock markets' strong reaction to tail risk during "bad" months when returns are negative and sentiment is bearish. During "good" months when returns are positive and sentiment is bullish, however, the markets' response to tail risk appears to be muted.

\section{Conclusions}

Using the quantile regression technique, this paper investigates the impact of time-varying tail risk on excess stock market returns at the different locations on the return distributions. The measure of time-varying extreme event risk is calculated following Kelly and Jiang (2014). Using a large cross section of stocks, their technique can capture the common tail risk dynamics experienced by all individual firms in the sample. Our findings point to a positive and statistically significant relation between the market excess returns and tail risk for part of the return distribution below the 40th quantile. The results support previously documented evidence on the role of sentiment on the equity risk premium whereby the risk premium is found to be larger during periods of bearish sentiment associated with falling stock prices and rising volatility. At the upper quantiles, we find no association between tail risk and the market excess returns, pointing to the absence of reaction to an increase in the likelihood of market crash during good states when sentiment is bullish. We also find that tail risk can only predict short-term variations in the excess stock market returns for forecast horizons of up to one year. The predictive power of tail risk vanishes at the three- and the five-year forecast horizons. This suggests that the significance of tail risk vanishes as time passes. Our results are robust to the choice of stock market index: we obtain similar results for both the CRSP value-weighted index and the S\&P 500 index. Finally, as a check for the robustness of our findings, results from the bivariate regressions for both the CRSP value-weighted index and the S\&P 500 index suggest that the explanatory power of tail risk at the lower quantiles of the return distributions remains strong even after we control for the impact of variables that have previously been documented to possess return predictability. 


\section{References}

Bakshi, G., Kapadia, N., Madan, D., 2003. Stock return characteristics, skew laws, and the differential pricing of individual equity options. Review of Financial Studies 16 (1), 101-143.

Barro, R. J., 2006. Rare disasters and asset markets in the twentieth century. Quarterly Journal of Economics 121 (3), 823-866.

Baur, D. G., Dimpfl, T., Jung, R. C., 2012. Stock return autocorrelations revisited: A quantile regression approach. Journal of Empirical Finance 19 (2), 254-265.

Bollerslev, T., Todorov, V., 2011. Tails, fears, and risk premia. Journal of Finance 66 (6), $2165-2211$.

Buchinsky, M., 1995. Estimating the asymptotic covariance matrix for quantile regression models: A monte carlo study. Journal of Econometrics 68, 303-338.

Chevapatrakul, T., 2014. Monetary environments and stock returns revisited: A quantile regression approach. Economics Letters 123 (2), 122-126.

Chevapatrakul, T., 2015. Monetary environments and stock returns: international evidence based on the quantile regression technique. International Review of Financial Analysis 38, $83-108$.

Cox, J. C., Ingersoll, J. C., Ross, S. A., 1985. A theory of the term structure of interest rates. Econometrica 53, 385-407.

D'Agostino, R., 1970. Transformation to normality of the null distribution of $g_{1}$. Biometrika $57(3), 679-681$.

Gabaix, X., 2012. Variable rare disasters: An exactly solved framework for ten puzzles in macro-finance. Quarterly Journal of Economics 127, 645-700.

Gabaix, X., 2016. Power laws in economics: An introduction. Journal of Economic Perspectives $30(1), 185-206$.

Gebka, B., Wohar, M. E., 2013. Causality between trading volume and returns: Evidence from quantile regressions. International Review of Economics \& Finance 27, 144-159.

Glosten, L. R., Jagannathan, R., Runkle, D. A., 1993. On the relation between the expected value and the volatility of the nominal excess return on stocks. Journal of Finance 48 (5), $1779-1801$.

Gourio, F., 2012. Disaster risk and business cycles. American Economic Review 102, 2734-66.

Goyal, A., Welch, I., 2008. A comprehensive look at the empirical performance of equity permium prediction. Review of Financial Studies 21, 1455-1508. 
Hill, B., 1975. A simple general approach to inference about the tail of a distribution. Annals of Statistics 3 (5), 1163-1174.

Jarque, C. M., Bera, A. K., 1987. A test for normality of observations and regression residuals. International Statistical Review 55 (2), 163-172.

Kelly, B., Jiang, H., 2014. Tail risk and asset prices. Review of Financial Studies 27 (10), $2841-2871$.

Koenker, R., Bassett, G., 1978. Regression quantiles. Econometrica 46 (1), 33-50.

Koenker, R., Bassett, G., 1982. Robust tests for heteroscedasticity based on regression quantiles. Econometrica 50 (1), 43-62.

Koenker, R., Hallock, K. F., 2001. Quantile regression. Journal of Economic Perspectives 15, 143-156.

Lee, W. Y., Jiang, C. X., Indro, D. C., 2002. Stock market volatility, excess returns, and the role of investor sentiment. Journal of Banking \& Finance 26, 2277-2299.

Lettau, M., Ludvigson, S., 2003. Measuring and modeling variations in the risk-return trade-off. In: Ait-Shalia, Y., Hansen, L. P. (Eds.), Handbook of Financial Econometrics. New York University.

Mehra, R., Prescott, E. C., 1985. The equity premium: A puzzle. Journal of Monetary Economics $15(2), 145-161$.

Nath, H. B., Brooks, R. D., 2015. Assessing the idiosyncratic risk and stock returns relation in heteroskedasticity corrected predictive models using quantile regression. International Review of Economics \& Finance 38, 94-111.

Nelson, D. B., 1991. Conditional heteroskedasticity in asset returns: A new approach. Econometrica 59 (2), 347-370.

Racine, J. S., 2006. Consistent specification testing of heteroskedastic parametric regression quantile models with mixed data. Manuscript, McMaster University.

Rietz, T. A., 1988. The equity risk premium a solution. Journal of Monetary Economics 22 (1), $117-131$.

Shumway, T., 1997. The delisting bias in crsp data. Journal of Finance, 327-340.

Wachter, J. A., 2013. Can time-varying risk of rare disasters explain aggregate stock market volatility? Journal of Finance 68 (3), 987-1035.

Wu, S.-J., Lee, W.-M., 2015. Intertemporal risk-return relationships in bull and bear markets. International Review of Economics \& Finance 38, 308-325. 
Table 1

Descriptive Statistics for the Stock Market Returns \& the Tail Risk Measure

This table reports the means, standard deviations, minima, maxima, skewness, kurtosis and quantiles for the CRSP value-weighted excess return, the S\&P 500 excess return and the tail risk measure calculated following Eq. (2). The number of observations for non-missing returns in our sample after adjusting for delisted returns is $56,411,980$. For each month, the average and the minimum numbers of non-missing return observations are 111,929 and 69,523 respectively. For each month, the average number of stocks (observations) used in the calculation of tail risk is $2,423(5,647)$ while the number of stocks (observations) exceeding the threshold varies between 1,511 $(3,477)$ and $4,150(8,562)$. All the thresholds are negative with the average value of $-5.4 \%$.

\begin{tabular}{l|rrr}
\hline & CRSP & S\&P 500 & $\lambda$ \\
\hline Number of observations & 516 & 516 & 516 \\
Mean & 0.0051 & 0.0065 & 0.4394 \\
Standard deviation & 0.0460 & 0.0444 & 0.0448 \\
Minimum & -0.2324 & -0.2176 & 0.2910 \\
Maximum & 0.1610 & 0.1630 & 0.5662 \\
Skewness & -0.5318 & -0.4399 & -0.2229 \\
Kurtosis & 1.9398 & 1.8860 & -0.1339 \\
$10^{\text {th }}$ quantile & -0.0490 & -0.0458 & 0.3818 \\
$25^{\text {th }}$ quantile & -0.0212 & -0.0189 & 0.4091 \\
Median & 0.0088 & 0.0092 & 0.4416 \\
$75^{\text {th }}$ quantile & 0.0353 & 0.0357 & 0.4750 \\
$90^{\text {th }}$ quantile & 0.0565 & 0.0572 & 0.4967 \\
\hline
\end{tabular}




\section{Table 2}

\section{Quantile Regression Model Specification Test Results}

This table reports the results from the nonparametric heteroskedasticity-consistent model specification test, proposed by Racine (2006), for the conditional quantile function shown in Eq. (5). We set $\tau=0.05,0.1, \ldots, 0.9,0.95$ and $h=1,3,12,36,60$. The null hypothesis for the test is that the parametric regression quantile is correctly specified at the $100 \times \tau$ th quantile. The bootstrap procedures are used to generate the distribution of the test statistics under $H_{0}$. We report the $p$-values in the parentheses. Statistical significance at the 10\%, 5\% and $1 \%$ levels are indicated by $*, * *, * * *$ respectively.

\begin{tabular}{|c|c|c|c|c|c|c|c|c|c|c|}
\hline \multirow{2}{*}{$\tau$} & \multicolumn{5}{|c|}{ CRSP } & \multicolumn{5}{|c|}{ S\&P 500} \\
\hline & 1 & 3 & 12 & 36 & 60 & 1 & 3 & 12 & 36 & 60 \\
\hline 0.05 & $\begin{array}{c}-0.930 \\
(0.830)\end{array}$ & $\begin{array}{c}-0.668 \\
(0.226)\end{array}$ & $\begin{array}{l}-0.843 \\
(0.426)\end{array}$ & $\begin{array}{l}-0.690 \\
(0.193)\end{array}$ & $\begin{array}{l}-0.675 \\
(0.506)\end{array}$ & $\begin{array}{l}-0.950 \\
(0.900)\end{array}$ & $\begin{array}{c}-0.694 \\
(0.100)\end{array}$ & $\begin{array}{c}-0.719 \\
(0.281)\end{array}$ & $\begin{array}{c}-0.690 \\
(0.170)\end{array}$ & $\begin{array}{c}0.675 \\
(0.376)\end{array}$ \\
\hline 0.10 & $\begin{array}{l}-0.904 \\
(0.734)\end{array}$ & $\begin{array}{l}-0.705 \\
(0.456)\end{array}$ & $\begin{array}{c}-0.317^{*} \\
(0.080)\end{array}$ & $\begin{array}{l}-0.697 \\
(0.165)\end{array}$ & $\begin{array}{l}-0.711 \\
(0.764)\end{array}$ & $\begin{array}{l}-0.907 \\
(0.697)\end{array}$ & $\begin{array}{l}-0.763 \\
(0.376)\end{array}$ & $\begin{array}{l}-0.594 \\
(0.238)\end{array}$ & $\begin{array}{l}-0.697 \\
(0.153)\end{array}$ & $\begin{array}{c}-0.668^{* *} \\
(0.035)\end{array}$ \\
\hline 0.20 & $\begin{array}{l}-0.771 \\
(0.208)\end{array}$ & $\begin{array}{l}-0.708 \\
(0.862)\end{array}$ & $\begin{array}{l}-0.726 \\
(0.311)\end{array}$ & $\begin{array}{l}-0.700 \\
(0.113)\end{array}$ & $\begin{array}{l}-0.703 \\
(0.712)\end{array}$ & $\begin{array}{l}-0.750 \\
(0.190)\end{array}$ & $\begin{array}{l}-0.786 \\
(0.895)\end{array}$ & $\begin{array}{l}-1.027 \\
(0.734)\end{array}$ & $\begin{array}{l}-0.700 \\
(0.118)\end{array}$ & $\begin{array}{l}-0.703 \\
(0.677)\end{array}$ \\
\hline 0.30 & $\begin{array}{l}-0.768 \\
(0.238)\end{array}$ & $\begin{array}{l}-0.708 \\
(0.887)\end{array}$ & $\begin{array}{l}-1.107 \\
(0.912)\end{array}$ & $\begin{array}{l}-0.701 \\
(0.233)\end{array}$ & $\begin{array}{l}-0.698 \\
(0.584)\end{array}$ & $\begin{array}{l}-0.863 \\
(0.501)\end{array}$ & $\begin{array}{l}-0.781 \\
(0.702)\end{array}$ & $\begin{array}{l}-0.883 \\
(0.511)\end{array}$ & $\begin{array}{l}-0.701 \\
(0.386)\end{array}$ & $\begin{array}{l}-0.698 \\
(0.489)\end{array}$ \\
\hline 0.40 & $\begin{array}{l}-0.866 \\
(0.541)\end{array}$ & $\begin{array}{l}-0.704 \\
(0.366)\end{array}$ & $\begin{array}{l}-0.888 \\
(0.511)\end{array}$ & $\begin{array}{l}-0.708 \\
(0.807)\end{array}$ & $\begin{array}{l}-0.707 \\
(0.887)\end{array}$ & $\begin{array}{l}-0.828 \\
(0.401)\end{array}$ & $\begin{array}{l}-0.773 \\
(0.414)\end{array}$ & $\begin{array}{l}-0.510 \\
(0.165)\end{array}$ & $\begin{array}{l}-0.708 \\
(0.867)\end{array}$ & $\begin{array}{l}-0.706 \\
(0.571)\end{array}$ \\
\hline 0.50 & $\begin{array}{l}-0.915 \\
(0.912)\end{array}$ & $\begin{array}{l}-0.695 \\
(0.303)\end{array}$ & $\begin{array}{l}-0.771 \\
(0.376)\end{array}$ & $\begin{array}{l}-0.702 \\
(0.296)\end{array}$ & $\begin{array}{l}-0.702 \\
(0.298)\end{array}$ & $\begin{array}{l}-0.832 \\
(0.393)\end{array}$ & $\begin{array}{l}-0.785 \\
(0.957)\end{array}$ & $\begin{array}{c}0.095^{* *} \\
(0.028)\end{array}$ & $\begin{array}{l}-0.702 \\
(0.143)\end{array}$ & $\begin{array}{l}-0.702 \\
(0.436)\end{array}$ \\
\hline 0.60 & $\begin{array}{l}-0.928 \\
(0.980)\end{array}$ & $\begin{array}{l}-0.700 \\
(0.356)\end{array}$ & $\begin{array}{l}-0.553 \\
(0.198)\end{array}$ & $\begin{array}{l}-0.702 \\
(0.135)\end{array}$ & $\begin{array}{l}-0.695 \\
(0.456)\end{array}$ & $\begin{array}{l}-0.917 \\
(0.845)\end{array}$ & $\begin{array}{l}-0.771 \\
(0.421)\end{array}$ & $\begin{array}{l}-0.544 \\
(0.188)\end{array}$ & $\begin{array}{c}-0.702^{*} \\
(0.090)\end{array}$ & $\begin{array}{l}-0.695 \\
(0.281)\end{array}$ \\
\hline 0.70 & $\begin{array}{l}-0.910 \\
(0.842)\end{array}$ & $\begin{array}{l}-0.703 \\
(0.414)\end{array}$ & $\begin{array}{c}-0.607 \\
(0.228)\end{array}$ & $\begin{array}{l}-0.701 \\
(0.130)\end{array}$ & $\begin{array}{l}-0.704 \\
(0.870)\end{array}$ & $\begin{array}{l}-0.873 \\
(0.561)\end{array}$ & $\begin{array}{l}-0.782 \\
(0.897)\end{array}$ & $\begin{array}{l}-0.523 \\
(0.183)\end{array}$ & $\begin{array}{l}-0.701 \\
(0.155)\end{array}$ & $\begin{array}{l}-0.684 \\
(0.123)\end{array}$ \\
\hline 0.80 & $\begin{array}{l}-0.718 \\
(0.125)\end{array}$ & $\begin{array}{l}-0.706 \\
(0.554)\end{array}$ & $\begin{array}{c}-0.359^{*} \\
(0.090)\end{array}$ & $\begin{array}{c}-0.700^{*} \\
(0.073)\end{array}$ & $\begin{array}{l}-0.696 \\
(0.554)\end{array}$ & $\begin{array}{l}-0.794 \\
(0.266)\end{array}$ & $\begin{array}{l}-0.780 \\
(0.762)\end{array}$ & $\begin{array}{l}-0.658 \\
(0.268)\end{array}$ & $\begin{array}{c}-0.700^{*} \\
(0.085)\end{array}$ & $\begin{array}{l}-0.696 \\
(0.602)\end{array}$ \\
\hline 0.90 & $\begin{array}{c}-0.506^{* *} \\
(0.030)\end{array}$ & $\begin{array}{l}-0.705 \\
(0.679)\end{array}$ & $\begin{array}{l}-1.185 \\
(0.997)\end{array}$ & $\begin{array}{l}-0.696 \\
(0.266)\end{array}$ & $\begin{array}{l}-0.707 \\
(0.414)\end{array}$ & $\begin{array}{l}-0.690 \\
(0.145)\end{array}$ & $\begin{array}{l}-0.742 \\
(0.113)\end{array}$ & $\begin{array}{l}-1.113 \\
(0.875)\end{array}$ & $\begin{array}{l}-0.696 \\
(0.609)\end{array}$ & $\begin{array}{l}-0.707 \\
(0.406)\end{array}$ \\
\hline 0.95 & $\begin{array}{c}-0.367^{* *} \\
(0.013)\end{array}$ & $\begin{array}{l}-0.707 \\
(0.907)\end{array}$ & $\begin{array}{l}-1.181 \\
(0.965)\end{array}$ & $\begin{array}{l}-0.688 \\
(0.484)\end{array}$ & $\begin{array}{l}-0.700 \\
(0.571)\end{array}$ & $\begin{array}{l}-0.695 \\
(0.118)\end{array}$ & $\begin{array}{l}-0.771 \\
(0.541)\end{array}$ & $\begin{array}{l}-0.969 \\
(0.602)\end{array}$ & $\begin{array}{l}-0.688 \\
(0.258)\end{array}$ & $\begin{array}{l}-0.700 \\
(0.531)\end{array}$ \\
\hline
\end{tabular}


Table 3

Quantile Regression Results

This table reports the quantile regression results for the model shown in Eq. (5). We set $\tau=0.05,0.1, \ldots, 0.9,0.95$ and $h=1,3,12,36,60$. The bootstrapped standard errors, calculated following Buchinsky (1995), are shown in the parentheses. Statistical significance at the $10 \%, 5 \%$ and $1 \%$ levels are indicated by $*, * *, * * *$ respectively.

\begin{tabular}{|c|c|c|c|c|c|c|c|c|c|c|}
\hline & \multicolumn{5}{|c|}{ CRSP } & \multicolumn{5}{|c|}{ S\&P 500} \\
\hline & 1 & 3 & 12 & 36 & 60 & 1 & 3 & 12 & 36 & 60 \\
\hline$\hat{\beta}_{\mathrm{OLS}}$ & $\begin{array}{c}0.004^{* *} \\
(0.002)\end{array}$ & $\begin{array}{c}0.002 \\
(0.002)\end{array}$ & $\begin{array}{c}0.003 \\
(0.002)\end{array}$ & $\begin{array}{l}-0.002 \\
(0.002)\end{array}$ & $\begin{array}{l}-0.000 \\
(0.002)\end{array}$ & $\begin{array}{c}0.004^{* *} \\
(0.002)\end{array}$ & $\begin{array}{c}0.002 \\
(0.002)\end{array}$ & $\begin{array}{c}0.004^{*} \\
(0.002)\end{array}$ & $\begin{array}{c}-0.001 \\
(0.002)\end{array}$ & $\begin{array}{c}0.001 \\
(0.002)\end{array}$ \\
\hline$\hat{\beta}_{0.05}$ & $\begin{array}{c}0.017^{* * *} \\
(0.005)\end{array}$ & $\begin{array}{c}0.015^{* * *} \\
(0.005)\end{array}$ & $\begin{array}{c}0.011^{* * *} \\
(0.005)\end{array}$ & $\begin{array}{c}-0.004 \\
(0.008)\end{array}$ & $\begin{array}{c}0.000 \\
(0.007)\end{array}$ & $\begin{array}{c}0.016^{* * *} \\
(0.005)\end{array}$ & $\begin{array}{c}0.016^{* * *} \\
(0.005)\end{array}$ & $\begin{array}{c}0.011^{* *} \\
(0.005)\end{array}$ & $\begin{array}{c}-0.000 \\
(0.007)\end{array}$ & $\begin{array}{c}0.005 \\
(0.007)\end{array}$ \\
\hline$\hat{\beta}_{0.10}$ & $\begin{array}{c}0.014^{* * *} \\
(0.003)\end{array}$ & $\begin{array}{c}0.010 * * \\
(0.011)\end{array}$ & $\begin{array}{c}0.012^{* * *} \\
(0.004)\end{array}$ & $\begin{array}{c}0.003 \\
(0.006)\end{array}$ & $\begin{array}{c}-0.006 \\
(0.006)\end{array}$ & $\begin{array}{c}0.012^{* * *} \\
(0.003)\end{array}$ & $\begin{array}{c}0.011^{* *} \\
(0.005)\end{array}$ & $\begin{array}{c}0.011^{* * *} \\
(0.004)\end{array}$ & $\begin{array}{c}0.005 \\
(0.006)\end{array}$ & $\begin{array}{l}-0.004 \\
(0.006)\end{array}$ \\
\hline$\hat{\beta}_{0.20}$ & $\begin{array}{c}0.009^{* * *} \\
(0.003)\end{array}$ & $\begin{array}{c}0.007^{* * *} \\
(0.002)\end{array}$ & $\begin{array}{l}0.005^{*} \\
(0.003)\end{array}$ & $\begin{array}{l}-0.001 \\
(0.002)\end{array}$ & $\begin{array}{c}-0.003 \\
(0.002)\end{array}$ & $\begin{array}{c}0.007^{* *} \\
(0.003)\end{array}$ & $\begin{array}{c}0.006^{* * *} \\
(0.002)\end{array}$ & $\begin{array}{c}0.006^{* *} \\
(0.003)\end{array}$ & $\begin{array}{c}-0.001 \\
(0.002)\end{array}$ & $\begin{array}{c}-0.001 \\
(0.002)\end{array}$ \\
\hline$\hat{\beta}_{0.30}$ & $\begin{array}{c}0.006 * * \\
(0.003)\end{array}$ & $\begin{array}{c}0.004^{*} \\
(0.064)\end{array}$ & $\begin{array}{c}0.005^{* *} \\
(0.002)\end{array}$ & $\begin{array}{c}0.001 \\
(0.002)\end{array}$ & $\begin{array}{c}-0.002 \\
(0.003)\end{array}$ & $\begin{array}{c}0.006^{* *} \\
(0.002)\end{array}$ & $\begin{array}{l}0.004^{*} \\
(0.002)\end{array}$ & $\begin{array}{c}0.005 * * \\
(0.002)\end{array}$ & $\begin{array}{c}0.001 \\
(0.002)\end{array}$ & $\begin{array}{c}0.002 \\
(0.003)\end{array}$ \\
\hline$\hat{\beta}_{0.40}$ & $\begin{array}{c}0.003 \\
(0.004)\end{array}$ & $\begin{array}{c}0.001 \\
(0.004)\end{array}$ & $\begin{array}{c}0.006^{* *} \\
(0.002)\end{array}$ & $\begin{array}{c}0.002 \\
(0.003)\end{array}$ & $\begin{array}{c}0.000 \\
(0.004)\end{array}$ & $\begin{array}{c}0.002 \\
(0.003)\end{array}$ & $\begin{array}{c}0.001 \\
(0.002)\end{array}$ & $\begin{array}{c}0.004^{*} \\
(0.002)\end{array}$ & $\begin{array}{c}0.003 \\
(0.002)\end{array}$ & $\begin{array}{c}0.001 \\
(0.003)\end{array}$ \\
\hline$\hat{\beta}_{0.50}$ & $\begin{array}{c}0.002 \\
(0.002)\end{array}$ & $\begin{array}{c}0.001 \\
(0.002)\end{array}$ & $\begin{array}{c}0.001 \\
(0.002)\end{array}$ & $\begin{array}{c}0.001 \\
(0.002)\end{array}$ & $\begin{array}{c}0.000 \\
(0.002)\end{array}$ & $\begin{array}{c}0.001 \\
(0.003)\end{array}$ & $\begin{array}{c}0.000 \\
(0.002)\end{array}$ & $\begin{array}{c}0.002 \\
(0.002)\end{array}$ & $\begin{array}{c}0.001 \\
(0.002)\end{array}$ & $\begin{array}{c}0.002 \\
(0.002)\end{array}$ \\
\hline$\hat{\beta}_{0.60}$ & $\begin{array}{l}-0.001 \\
(0.003)\end{array}$ & $\begin{array}{c}(-0.002 \\
(0.002)\end{array}$ & $\begin{array}{l}-0.001 \\
(0.003)\end{array}$ & $\begin{array}{l}-0.001 \\
(0.002)\end{array}$ & $\begin{array}{c}-0.000 \\
(0.002)\end{array}$ & $\begin{array}{c}0.002 \\
(0.002)\end{array}$ & $\begin{array}{l}-0.001 \\
(0.002)\end{array}$ & $\begin{array}{c}0.001 \\
(0.002)\end{array}$ & $\begin{array}{c}0.001 \\
(0.002)\end{array}$ & $\begin{array}{c}0.001 \\
(0.002)\end{array}$ \\
\hline$\hat{\beta}_{0.70}$ & $\begin{array}{l}-0.002 \\
(0.003)\end{array}$ & $\begin{array}{c}-0.003 \\
(0.003)\end{array}$ & $\begin{array}{c}0.001 \\
(0.002)\end{array}$ & $\begin{array}{l}-0.001 \\
(0.003)\end{array}$ & $\begin{array}{l}-0.001 \\
(0.002)\end{array}$ & $\begin{array}{l}-0.000 \\
(0.003)\end{array}$ & $\begin{array}{c}-0.003 \\
(0.003)\end{array}$ & $\begin{array}{c}0.002 \\
(0.002)\end{array}$ & $\begin{array}{l}-0.000 \\
(0.003)\end{array}$ & $\begin{array}{c}0.002 \\
(0.002)\end{array}$ \\
\hline$\hat{\beta}_{0.80}$ & $\begin{array}{l}-0.002 \\
(0.003)\end{array}$ & $\begin{array}{l}-0.002 \\
(0.002)\end{array}$ & $\begin{array}{c}0.002 \\
(0.002)\end{array}$ & $\begin{array}{l}-0.002 \\
(0.002)\end{array}$ & $\begin{array}{c}0.002 \\
(0.002)\end{array}$ & $\begin{array}{c}0.000 \\
(0.003)\end{array}$ & $\begin{array}{l}-0.000 \\
(0.002)\end{array}$ & $\begin{array}{c}0.003 \\
(0.002)\end{array}$ & $\begin{array}{l}-0.001 \\
(0.002)\end{array}$ & $\begin{array}{c}0.003 \\
(0.002)\end{array}$ \\
\hline$\hat{\beta}_{0.90}$ & $\begin{array}{c}-0.002 \\
(0.003)\end{array}$ & $\begin{array}{c}0.002 \\
(0.004)\end{array}$ & $\begin{array}{c}0.002 \\
(0.004)\end{array}$ & $\begin{array}{l}-0.004 \\
(0.003)\end{array}$ & $\begin{array}{c}0.003 \\
(0.003)\end{array}$ & $\begin{array}{l}-0.002 \\
(0.003)\end{array}$ & $\begin{array}{l}-0.002 \\
(0.004)\end{array}$ & $\begin{array}{c}0.002 \\
(0.004)\end{array}$ & $\begin{array}{l}-0.004 \\
(0.004)\end{array}$ & $\begin{array}{c}0.004 \\
(0.003)\end{array}$ \\
\hline$\hat{\beta}_{0.95}$ & $\begin{array}{l}-0.002 \\
(0.004)\end{array}$ & $\begin{array}{l}-0.001 \\
(0.005)\end{array}$ & $\begin{array}{l}-0.001 \\
(0.005)\end{array}$ & $\begin{array}{c}-0.003 \\
(0.005)\end{array}$ & $\begin{array}{c}0.004 \\
(0.005)\end{array}$ & $\begin{array}{c}-0.002 \\
(0.005)\end{array}$ & $\begin{array}{l}-0.002 \\
(0.005)\end{array}$ & $\begin{array}{l}-0.001 \\
(0.005)\end{array}$ & $\begin{array}{c}-0.001 \\
(0.005)\end{array}$ & $\begin{array}{c}0.007 \\
(0.005)\end{array}$ \\
\hline
\end{tabular}




\section{Table 4}

\section{Slope Equality Test Results}

This table reports the results from the slope equality test of Koenker and Bassett (1982). We test the following null hypothesis $H_{0}: \beta_{\tau_{1}}=\beta_{\tau_{2}}$. The bootstrapped standard errors are shown in the parentheses. Statistical significance at the $10 \%, 5 \%$ and $1 \%$ levels are indicated by $*, * *$, and ${ }^{* * *}$ respectively.

\begin{tabular}{|c|c|c|c|c|c|c|c|c|c|c|}
\hline$\tau_{1}, \tau_{2}$ & \multicolumn{5}{|c|}{ CRSP } & \multicolumn{5}{|c|}{ S\&P 500} \\
\hline $0.05,0.95$ & $\begin{array}{c}0.019^{* * *} \\
(0.006)\end{array}$ & $\begin{array}{c}0.016^{* * *} \\
(0.006)\end{array}$ & $\begin{array}{c}0.013^{* *} \\
(0.005)\end{array}$ & $\begin{array}{l}-0.001 \\
(0.010)\end{array}$ & $\begin{array}{l}-0.003 \\
(0.007)\end{array}$ & $\begin{array}{c}0.018^{* * *} \\
(0.006)\end{array}$ & $\begin{array}{c}0.018^{* * *} \\
(0.006)\end{array}$ & $\begin{array}{c}0.012^{* *} \\
(0.006)\end{array}$ & $\begin{array}{c}0.009 \\
(0.009)\end{array}$ & $\begin{array}{c}-0.002 \\
(0.008)\end{array}$ \\
\hline $0.25,0.75$ & $\begin{array}{c}0.009 * * * \\
(0.003)\end{array}$ & $\begin{array}{c}0.009 * * * \\
(0.003)\end{array}$ & $\begin{array}{c}0.004 \\
(0.172)\end{array}$ & $\begin{array}{c}0.001 \\
(0.003)\end{array}$ & $\begin{array}{l}-0.001 \\
(0.003)\end{array}$ & $\begin{array}{c}0.006^{*} \\
(0.003)\end{array}$ & $\begin{array}{c}0.006^{*} \\
(0.003)\end{array}$ & $\begin{array}{c}0.001 \\
(0.003)\end{array}$ & $\begin{array}{l}-0.000 \\
(0.003)\end{array}$ & $\begin{array}{c}-0.002 \\
(0.003)\end{array}$ \\
\hline
\end{tabular}




\section{Table 5}

\section{Descriptive Statistics for the Alternative Return Predictors}

This table reports the descriptive statistics for the return predictors documented in Goyal and Welch (2008). The book-to-market ratio $(\mathrm{B} / \mathrm{M})$ is the ratio of the book value to the market value for the Dow Jones Industrial Average. Treasury-bill rates (TB) are the yields on the three-month Treasury bills. The long term yields (LTY) are the yields on long-term U.S. bonds from Ibbotson's Stocks, Bonds, Bills and Inflation Yearbook. The net equity expansion (NEE) is the ratio of the twelve-month moving sum of net issues by NYSE listed stocks to the total end-of-year market capitalization of NYSE stocks. Inflation (INF) is the growth rate of CPI from the Bureau of Labour Statistics. The long-term rates of return (LTR) are also from Ibbotson's Stocks, Bonds, Bills and Inflation Yearbook. Stock variance (SV) is computed as the sum of squared daily returns on the S\&P 500 index. The default yield spread (DYS) is the difference between BAA and AAA-rated corporate bond yields. The dividend price ratio $(\mathrm{D} / \mathrm{P})$ is the difference between the $\log$ of dividends and the log of prices. The dividend payout ratio $(\mathrm{D} / \mathrm{E})$ is the difference between the log of dividends and the log of earnings. The earnings price ratio $(\mathrm{E} / \mathrm{P})$ is the difference between the log of earnings and the log of prices. The term spread (TS) is the difference between the yield on long-term government bonds and the yield on Treasury bills.

\begin{tabular}{l|rrrrrrrrrrrr}
\hline & $T$ & Mean & SD & Median & Min & Max & Skewness & Kurtosis & $10^{\text {th }}$ & $25^{\text {th }}$ & $75^{\text {th }}$ & $90^{\text {th }}$ \\
\hline B/M & 516 & 0.487 & 0.289 & 0.361 & 0.121 & 1.207 & 0.837 & -0.617 & 0.185 & 0.279 & 0.724 & 0.972 \\
TB & 516 & 0.049 & 0.035 & 0.050 & 0.000 & 0.163 & 0.508 & 0.222 & 0.001 & 0.019 & 0.071 & 0.090 \\
LTY & 516 & 0.071 & 0.028 & 0.070 & 0.020 & 0.148 & 0.450 & -0.223 & 0.035 & 0.049 & 0.085 & 0.112 \\
NEE & 516 & 0.008 & 0.019 & 0.011 & -0.058 & 0.046 & -0.667 & 0.464 & -0.019 & -0.002 & 0.022 & 0.031 \\
INF & 516 & 0.003 & 0.004 & 0.003 & -0.019 & 0.018 & -0.109 & 2.744 & -0.001 & 0.001 & 0.005 & 0.008 \\
LTR & 516 & 0.007 & 0.031 & 0.008 & -0.112 & 0.152 & 0.371 & 2.358 & -0.030 & -0.012 & 0.025 & 0.041 \\
SV & 516 & 0.002 & 0.005 & 0.001 & 0.000 & 0.071 & 9.307 & 109.428 & 0.001 & 0.001 & 0.002 & 0.005 \\
DYS & 516 & 0.011 & 0.005 & 0.010 & 0.006 & 0.034 & 1.697 & 3.603 & 0.007 & 0.008 & 0.013 & 0.017 \\
D/P & 516 & -3.219 & 1.686 & -4.054 & -6.008 & 2.107 & 0.594 & -0.485 & -4.505 & -4.240 & -1.557 & -0.986 \\
D/E & 516 & -0.800 & 0.341 & -0.861 & -1.244 & 1.380 & 3.135 & 15.225 & -1.131 & -0.975 & -0.668 & -0.511 \\
E/P & 516 & -2.419 & 1.799 & -3.288 & -5.203 & 2.924 & 0.541 & -0.870 & -4.704 & -3.612 & -0.568 & 0.081 \\
TS & 516 & 0.021 & 0.015 & 0.024 & -0.037 & 0.046 & -0.756 & 0.415 & 0.001 & 0.011 & 0.033 & 0.039 \\
\hline
\end{tabular}




\section{Table 6}

\section{The Quantile Regression Results for the Alternative Specification (CRSP)}

This table reports the quantile regression results for the model shown in Eq. (7). The model is estimated for the CRSP value-weighted index returns, setting $\tau=0.05,0.3,0.5,0.8, \ldots, 0.95$ and $h=1$. For comparison purposes, the table also reports the OLS estimates of the parameter on the tail risk measure (second column) and the parameter on the alternative predictor (the last column) The bootstrapped standard errors, calculated following Buchinsky (1995), are shown in the parentheses. Statistical significance at the $10 \%, 5 \%$ and $1 \%$ levels are indicated by $*, * *, * * *$ respectively.

\begin{tabular}{|c|c|c|c|c|c|c|c|}
\hline Alt. Predictor & $\hat{\beta}_{\text {OLS }}$ & $\hat{\beta}_{0.05}$ & $\hat{\beta}_{0.30}$ & $\hat{\beta}_{0.50}$ & $\hat{\beta}_{0.80}$ & $\hat{\beta}_{0.95}$ & $\hat{\gamma}_{\text {OLS }}$ \\
\hline $\mathrm{B} / \mathrm{M}$ & $\begin{array}{r}0.004^{* *} \\
(0.002)\end{array}$ & $\begin{array}{r}0.017^{* * *} \\
(0.005)\end{array}$ & $\begin{array}{r}0.007^{* *} \\
(0.003)\end{array}$ & $\begin{array}{r}0.002 \\
(0.002)\end{array}$ & $\begin{array}{l}-0.002 \\
(0.003)\end{array}$ & $\begin{array}{r}-0.006 \\
(0.005)\end{array}$ & $\begin{array}{r}0.000 \\
(0.002)\end{array}$ \\
\hline $\mathrm{TB}$ & $\begin{array}{r}0.006^{* * *} \\
(0.002)\end{array}$ & $\begin{array}{r}0.02^{* * *} \\
(0.005)\end{array}$ & $\begin{array}{r}0.009^{* * *} \\
(0.003)\end{array}$ & $\begin{array}{r}0.003 \\
(0.003)\end{array}$ & $\begin{array}{r}-0.002 \\
(0.003)\end{array}$ & $\begin{array}{r}0.000 \\
(0.005)\end{array}$ & $\begin{array}{c}-0.004^{*} \\
(0.002)\end{array}$ \\
\hline LTY & $\begin{array}{r}0.006^{* * *} \\
(0.002)\end{array}$ & $\begin{array}{r}0.021^{* * *} * \\
(0.005)\end{array}$ & $\begin{array}{r}0.01^{* * *} \\
(0.004)\end{array}$ & $\begin{array}{r}0.004 \\
(0.003)\end{array}$ & $\begin{array}{l}-0.003 \\
(0.003)\end{array}$ & $\begin{array}{l}-0.005 \\
(0.005)\end{array}$ & $\begin{array}{l}-0.004 \\
(0.002)\end{array}$ \\
\hline NEE & $\begin{array}{c}0.004^{* *} \\
(0.002)\end{array}$ & $\begin{array}{r}0.019^{* * *} \\
(0.005)\end{array}$ & $\begin{array}{c}0.006^{*} \\
(0.003)\end{array}$ & $\begin{array}{r}0.002 \\
(0.002)\end{array}$ & $\begin{array}{r}-0.002 \\
(0.003)\end{array}$ & $\begin{array}{r}-0.003 \\
(0.004)\end{array}$ & $\begin{array}{l}-0.001 \\
(0.002)\end{array}$ \\
\hline INF & $\begin{array}{r}0.004^{* *} \\
(0.002)\end{array}$ & $\begin{array}{r}0.017^{* * *} \\
(0.004)\end{array}$ & $\begin{array}{l}0.005^{*} \\
(0.003)\end{array}$ & $\begin{array}{r}0.003 \\
(0.002)\end{array}$ & $\begin{array}{l}-0.002 \\
(0.003)\end{array}$ & $\begin{array}{l}-0.001 \\
(0.004)\end{array}$ & $\begin{array}{l}-0.003 \\
(0.002)\end{array}$ \\
\hline LTR & $\begin{array}{r}0.004^{* *} \\
(0.002)\end{array}$ & $\begin{array}{r}0.017^{* * *} \\
(0.005)\end{array}$ & $\begin{array}{r}0.007^{* *} \\
(0.003)\end{array}$ & $\begin{array}{r}0.001 \\
(0.002)\end{array}$ & $\begin{array}{r}-0.003 \\
(0.003)\end{array}$ & $\begin{array}{r}-0.002 \\
(0.004)\end{array}$ & $\begin{array}{l}0.004^{*} \\
(0.002)\end{array}$ \\
\hline SV & $\begin{array}{r}0.003 \\
(0.002)\end{array}$ & $\begin{array}{r}0.012^{* *} \\
(0.005)\end{array}$ & $\begin{array}{r}0.005^{* *} \\
(0.002)\end{array}$ & $\begin{array}{r}0.001 \\
(0.002)\end{array}$ & $\begin{array}{r}0.001 \\
(0.003)\end{array}$ & $\begin{array}{r}0.004 \\
(0.004)\end{array}$ & $\begin{array}{l}-0.004^{*} \\
(0.002)\end{array}$ \\
\hline DYS & $\begin{array}{c}0.004^{* *} \\
(0.002)\end{array}$ & $\begin{array}{r}0.017^{* * *} \\
(0.005)\end{array}$ & $\begin{array}{r}0.007^{* *} \\
(0.003)\end{array}$ & $\begin{array}{r}0.001 \\
(0.002)\end{array}$ & $\begin{array}{r}-0.001 \\
(0.003)\end{array}$ & $\begin{array}{r}0.000 \\
(0.005)\end{array}$ & $\begin{array}{r}0.002 \\
(0.002)\end{array}$ \\
\hline $\mathrm{D} / \mathrm{P}$ & $\begin{array}{r}0.005^{* *} \\
(0.002)\end{array}$ & $\begin{array}{r}0.019^{* * *} \\
(0.004)\end{array}$ & $\begin{array}{r}0.008^{* * *} \\
(0.003)\end{array}$ & $\begin{array}{r}0.003 \\
(0.003)\end{array}$ & $\begin{array}{l}-0.003 \\
(0.004)\end{array}$ & $\begin{array}{l}-0.002 \\
(0.005)\end{array}$ & $\begin{array}{r}0.002 \\
(0.002)\end{array}$ \\
\hline $\mathrm{D} / \mathrm{E}$ & $\begin{array}{r}0.004^{* *} \\
(0.002)\end{array}$ & $\begin{array}{r}0.02^{* * *} \\
(0.006)\end{array}$ & $\begin{array}{r}0.007^{* *} \\
(0.003)\end{array}$ & $\begin{array}{r}0.002 \\
(0.003)\end{array}$ & $\begin{array}{r}-0.004 \\
(0.003)\end{array}$ & $\begin{array}{l}-0.001 \\
(0.004)\end{array}$ & $\begin{array}{r}0.001 \\
(0.002)\end{array}$ \\
\hline $\mathrm{E} / \mathrm{P}$ & $\begin{array}{r}0.005^{* *} \\
(0.002)\end{array}$ & $\begin{array}{r}0.018^{* * *} \\
(0.005)\end{array}$ & $\begin{array}{r}0.008^{* * *} \\
(0.003)\end{array}$ & $\begin{array}{r}0.003 \\
(0.003)\end{array}$ & $\begin{array}{r}-0.004 \\
(0.003)\end{array}$ & $\begin{array}{r}-0.003 \\
(0.005)\end{array}$ & $\begin{array}{r}0.002 \\
(0.002)\end{array}$ \\
\hline TS & $\begin{array}{r}0.004^{* *} \\
(0.002)\end{array}$ & $\begin{array}{r}0.013^{* * *} \\
(0.005)\end{array}$ & $\begin{array}{r}0.005^{*} \\
(0.003)\end{array}$ & $\begin{array}{r}0.001 \\
(0.003)\end{array}$ & $\begin{array}{r}-0.002 \\
(0.003)\end{array}$ & $\begin{array}{r}-0.002 \\
(0.004)\end{array}$ & $\begin{array}{r}0.003 \\
(0.002)\end{array}$ \\
\hline
\end{tabular}




\section{Table 7}

\section{The Quantile Regression Results for the Alternative Specification (S\&P 500)}

This table reports the quantile regression results for the model shown in Eq. (7). The model is estimated for the S\&P 500 index returns, setting $\tau=0.05,0.3,0.5,0.8, \ldots, 0.95$ and $h=1$. For comparison purposes, the table also reports the OLS estimates of the parameter on the tail risk measure (second column) and the parameter on the alternative predictor (the last column) The bootstrapped standard errors, calculated following Buchinsky (1995), are shown in the parentheses. Statistical significance at the $10 \%, 5 \%$ and $1 \%$ levels are indicated by $*,{ }^{* *},{ }^{* *}$ respectively.

\begin{tabular}{|c|c|c|c|c|c|c|c|}
\hline Alt. Predictor & $\hat{\beta}_{\mathrm{OLS}}$ & $\hat{\beta}_{0.05}$ & $\hat{\beta}_{0.30}$ & $\hat{\beta}_{0.50}$ & $\hat{\beta}_{0.80}$ & $\hat{\beta}_{0.95}$ & $\hat{\gamma}_{\mathrm{OLS}}$ \\
\hline \multirow{2}{*}{$\mathrm{B} / \mathrm{M}$} & $0.004^{* *}$ & $0.017^{* * *}$ & $0.006^{* *}$ & 0.003 & 0.001 & -0.006 & 0.000 \\
\hline & $(0.002)$ & $(0.005)$ & $(0.003)$ & $(0.003)$ & $(0.003)$ & $(0.004)$ & $(0.002)$ \\
\hline \multirow{2}{*}{ TB } & $0.005^{* *}$ & $0.018^{* * *}$ & $0.007^{* *}$ & 0.002 & 0.001 & -0.006 & -0.002 \\
\hline & $(0.002)$ & $(0.005)$ & $(0.003)$ & $(0.003)$ & $(0.003)$ & $(0.005)$ & $(0.002)$ \\
\hline \multirow{2}{*}{ LTY } & $0.005^{* *}$ & $0.018^{* * *}$ & $0.007^{* *}$ & 0.002 & 0.000 & -0.007 & -0.001 \\
\hline & $(0.002)$ & $(0.006)$ & $(0.004)$ & $(0.003)$ & $(0.004)$ & $(0.006)$ & $(0.002)$ \\
\hline \multirow{2}{*}{ NEE } & $0.004^{* *}$ & $0.014^{* *}$ & $0.005^{* *}$ & 0.002 & 0.000 & -0.004 & -0.001 \\
\hline & $(0.002)$ & $(0.006)$ & $(0.002)$ & $(0.003)$ & $(0.003)$ & $(0.005)$ & $(0.002)$ \\
\hline \multirow{2}{*}{ INF } & $0.004^{* *}$ & $0.017^{* * *}$ & $0.004^{*}$ & 0.002 & 0.000 & -0.001 & -0.002 \\
\hline & $(0.002)$ & $(0.005)$ & $(0.003)$ & $(0.003)$ & $(0.004)$ & $(0.005)$ & $(0.002)$ \\
\hline \multirow{2}{*}{ LTR } & $0.004^{* *}$ & $0.015^{* * *}$ & $0.006^{* *}$ & 0.001 & 0.000 & -0.001 & $0.003^{*}$ \\
\hline & $(0.002)$ & $(0.005)$ & $(0.002)$ & $(0.003)$ & $(0.004)$ & $(0.003)$ & $(0.002)$ \\
\hline \multirow{2}{*}{ SV } & 0.003 & 0.01 & 0.004 & 0.000 & 0.004 & 0.005 & $-0.004^{* *}$ \\
\hline & $(0.002)$ & $(0.006)$ & $(0.003)$ & $(0.003)$ & $(0.003)$ & $(0.005)$ & $(0.002)$ \\
\hline \multirow{2}{*}{ DYS } & $0.004^{* *}$ & $0.013^{* *}$ & $0.006^{* *}$ & 0.001 & 0.000 & -0.001 & 0.002 \\
\hline & $(0.002)$ & (0.006) & $(0.003)$ & $(0.003)$ & $(0.003)$ & $(0.005)$ & $(0.002)$ \\
\hline \multirow{2}{*}{$\mathrm{D} / \mathrm{P}$} & $0.005^{* *}$ & $0.018^{* * *}$ & $0.006^{* *}$ & 0.003 & -0.001 & -0.004 & 0.001 \\
\hline & $(0.002)$ & $(0.005)$ & $(0.003)$ & $(0.003)$ & $(0.004)$ & $(0.005)$ & $(0.002)$ \\
\hline \multirow{2}{*}{$\mathrm{D} / \mathrm{E}$} & $0.004^{* *}$ & $0.018^{* * *}$ & $0.006^{* *}$ & 0.001 & -0.001 & 0.000 & 0.000 \\
\hline & $(0.002)$ & $(0.006)$ & $(0.003)$ & $(0.003)$ & $(0.003)$ & $(0.005)$ & $(0.002)$ \\
\hline \multirow{2}{*}{$\mathrm{E} / \mathrm{P}$} & $0.005^{* *}$ & $0.015^{* * *}$ & $0.006^{* *}$ & 0.003 & -0.001 & -0.003 & 0.001 \\
\hline & $(0.002)$ & $(0.005)$ & $(0.003)$ & $(0.003)$ & $(0.003)$ & $(0.005)$ & $(0.002)$ \\
\hline \multirow{2}{*}{ TS } & $0.004^{* *}$ & $0.018^{* * *}$ & $0.005^{*}$ & 0.001 & 0.000 & -0.001 & 0.001 \\
\hline & $(0.002)$ & $(0.005)$ & $(0.003)$ & $(0.003)$ & $(0.004)$ & $(0.005)$ & $(0.002)$ \\
\hline
\end{tabular}




\section{Figure 1}

Time series plots of the stock returns and the tail risk measure

Figures $1 \mathrm{a}$ and $1 \mathrm{~b}$ below show the time series of the tail risk measure and one-year ahead returns on the CRSP value-weighted index and the S\&P 500 index, respectively. The tail risk is calculated following Eq. (2). The sample period is between January 1973 and December 2015.

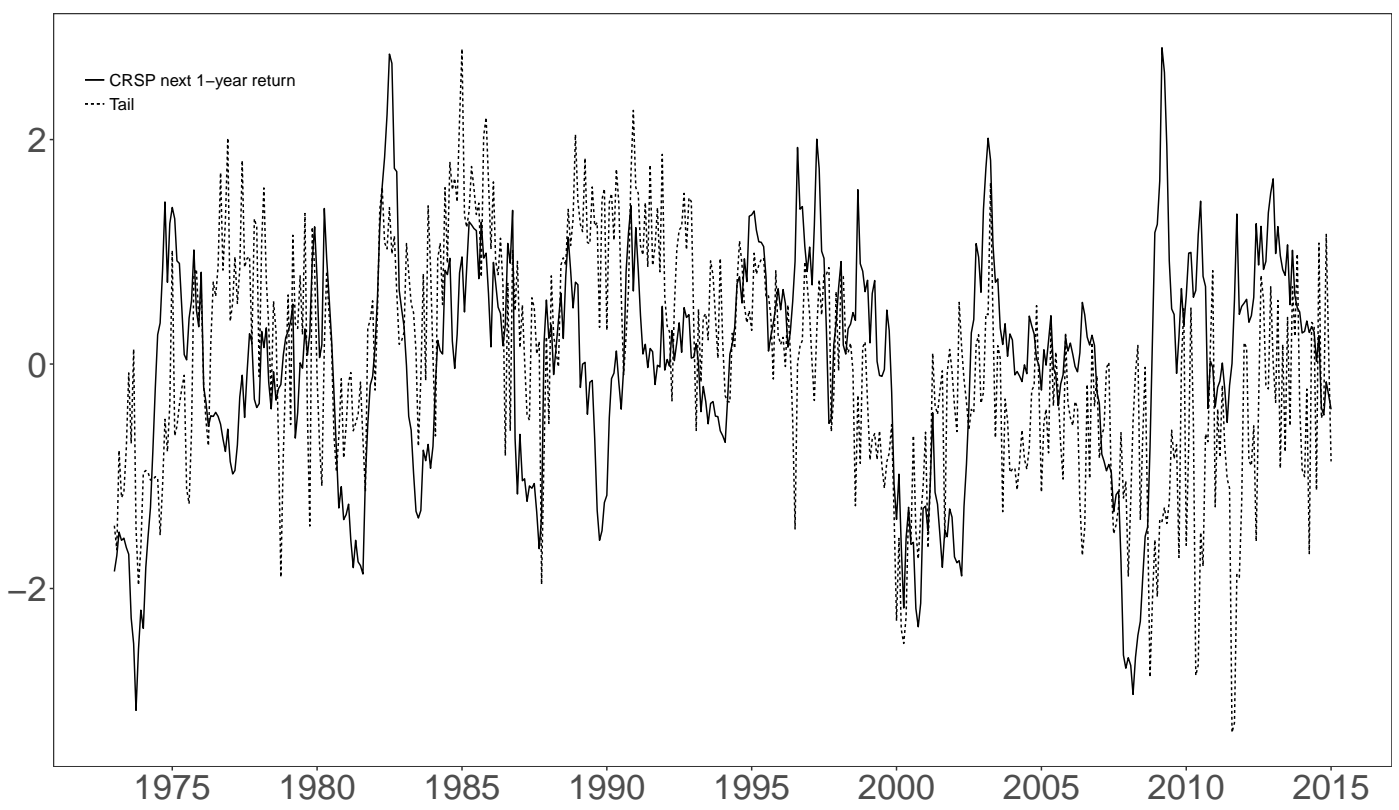

(a) CRSP Returns \& Tail

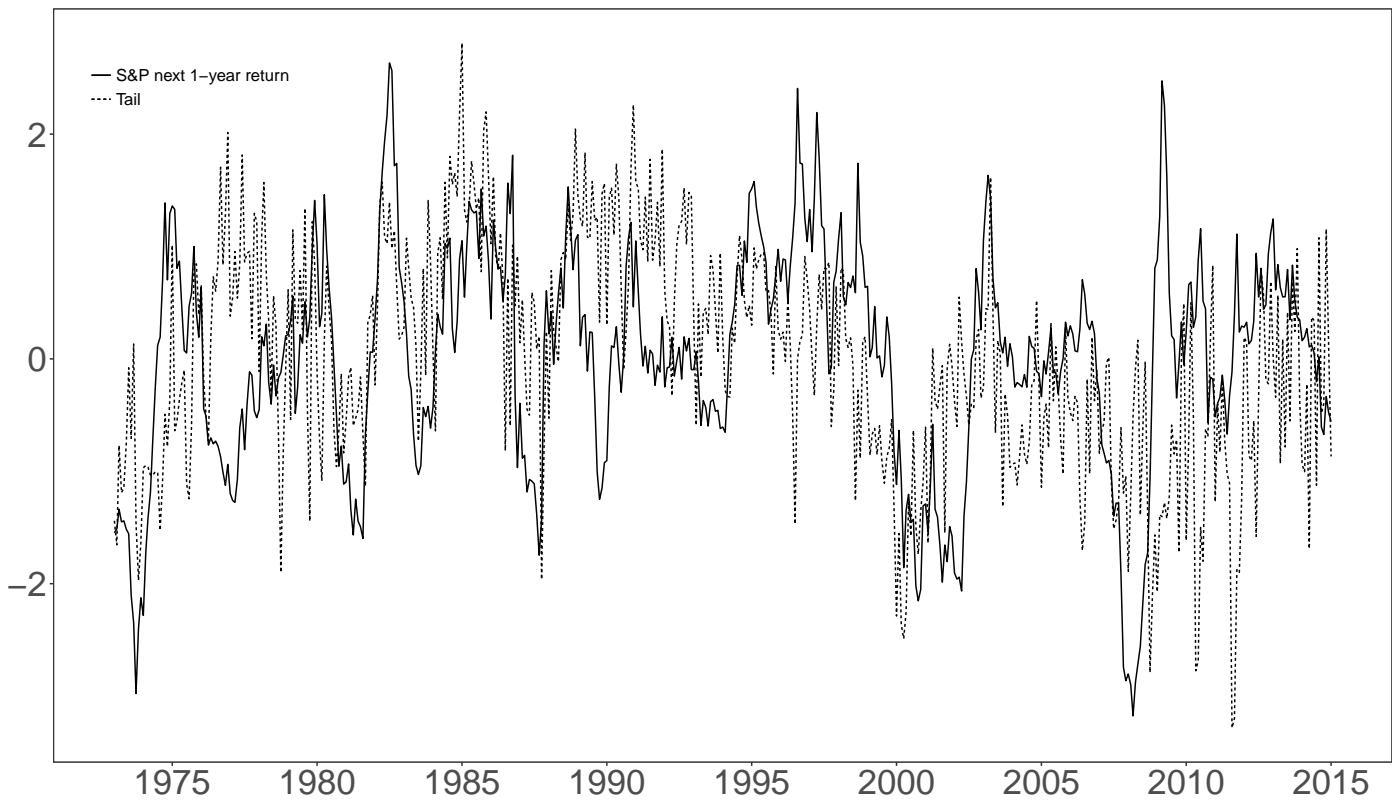

(b) S\&P 500 Returns \& Tail 


\section{Figure 2}

\section{Quantile Process Estimates}

This figure shows plots of the quantile process estimates of the slope parameter $\beta_{\tau}$ for Eq. (5) where $\tau=$ $0.05,0.08,0.11, \ldots, 0.95$ and $h=1,3,12$. The $90 \%$ confidence intervals are depicted by the shade areas in the plots.

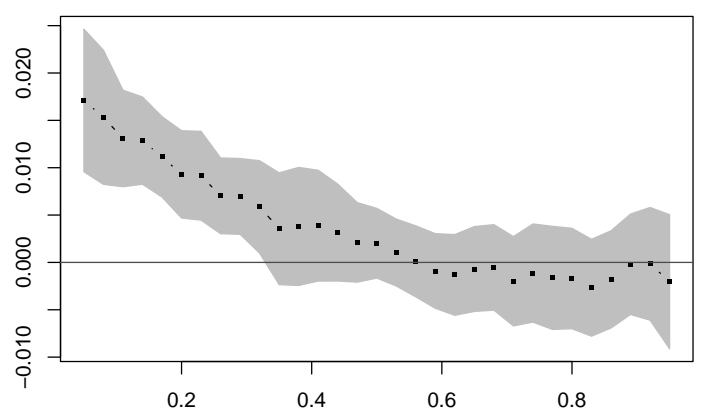

(a) CRSP (1-Month Forecast Horizon)

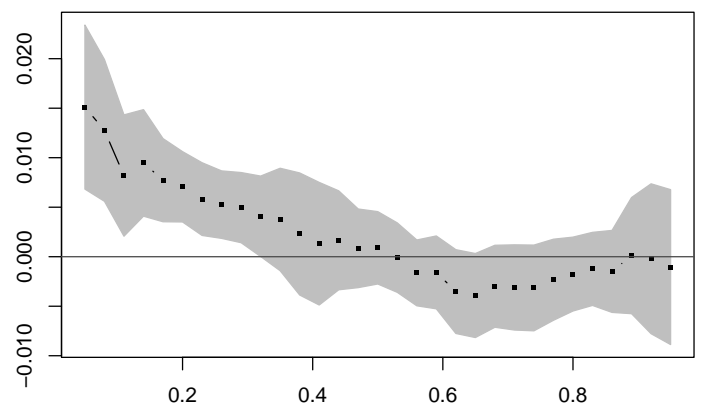

(c) CRSP (3-Month Forecast Horizon)

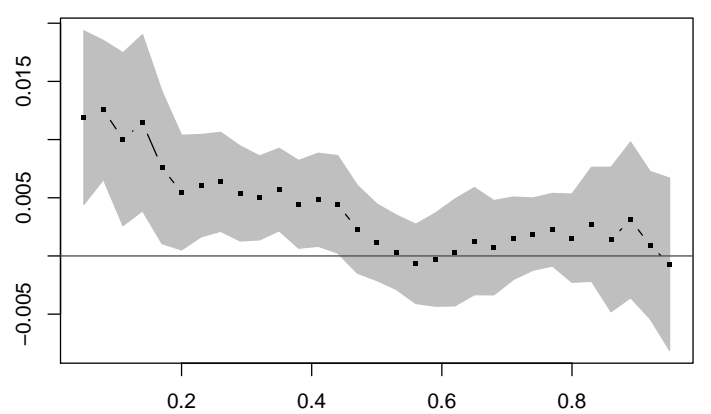

(e) CRSP (1-Year Forecast Horizon)

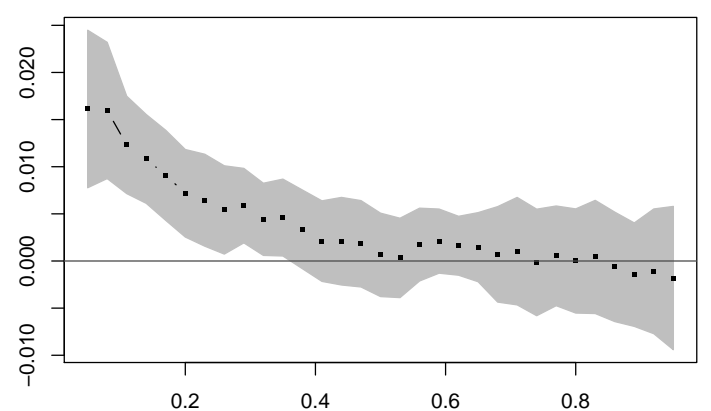

(b) S\&P 500 (1-Month Forecast Horizon)

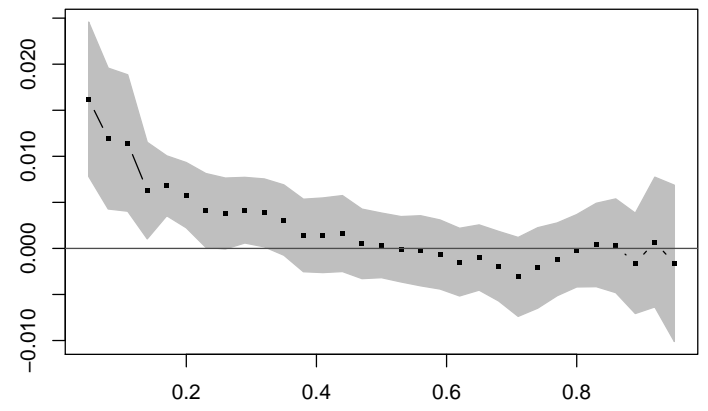

(d) S\&P 500 (3-Month Forecast Horizon)

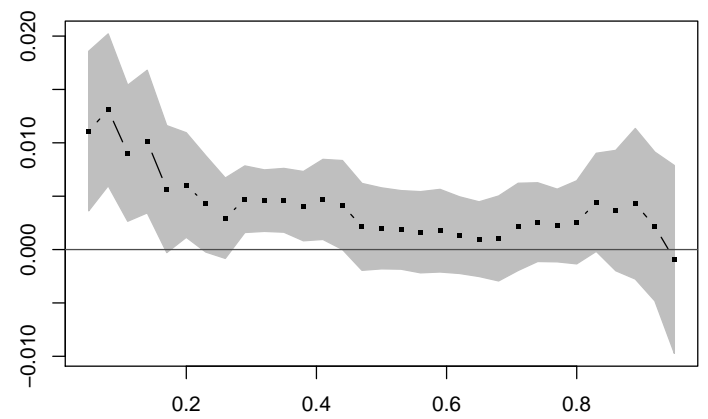

(f) S\&P 500 (1-Year Forecast Horizon) 


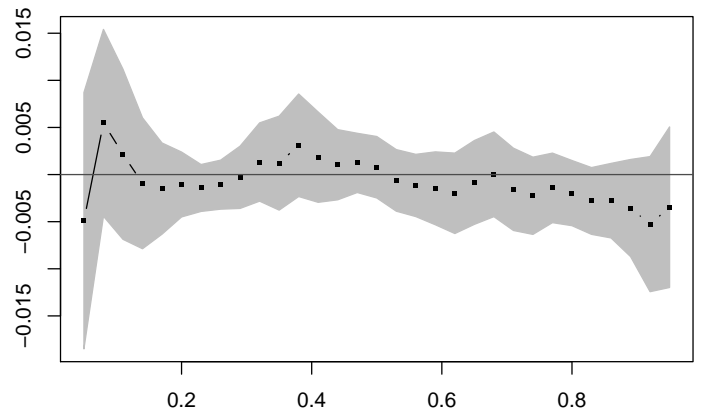

(g) CRSP (3-Year Forecast Horizon)

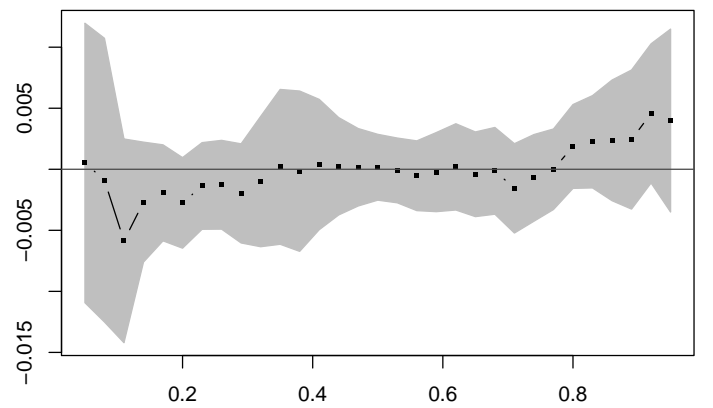

(i) CRSP (5-Year Forecast Horizon)

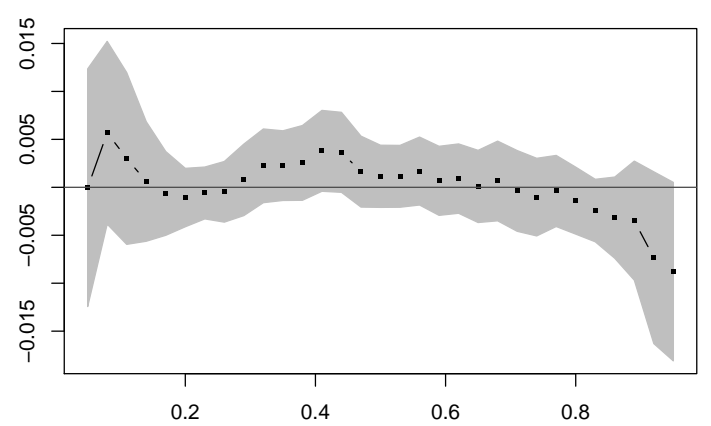

(h) S\&P 500 (3-Year Forecast Horizon)

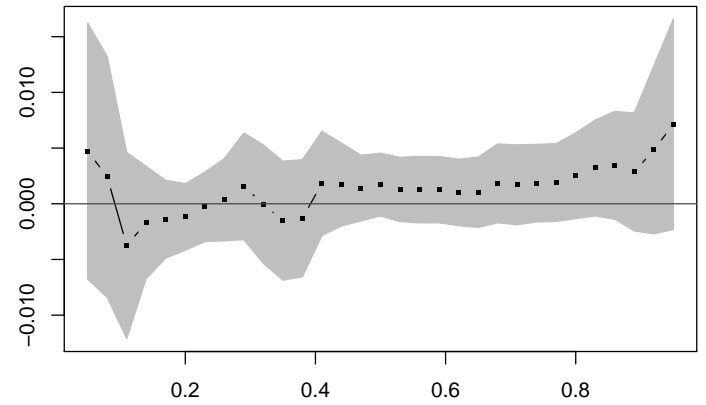

(j) S\&P 500 (5-Year Forecast Horizon) 


\section{Figure 3}

\section{Bivariate Quantile Process Estimates (CRSP)}

This figure shows plots of the quantile process estimates of the slope parameter on tail risk $\beta_{\tau}$ for Eq. (7) where $\tau=0.05,0.08,0.11, \ldots, 0.95$ and $h=1$. The dependent variable is the CRSP value-weighted index return. Each plot depicts the quantile process estimate for the tail risk parameter when an alternative predictor, as shown in the caption under the plot, is included in the model as an additional regressor. The $90 \%$ confidence intervals are depicted by the shade areas in the plots.

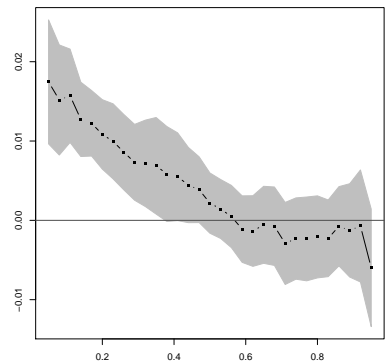

(a) $\mathrm{B} / \mathrm{M}$

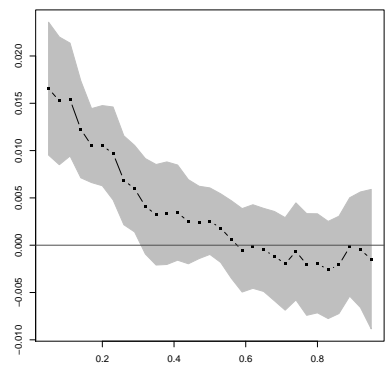

(e) INF

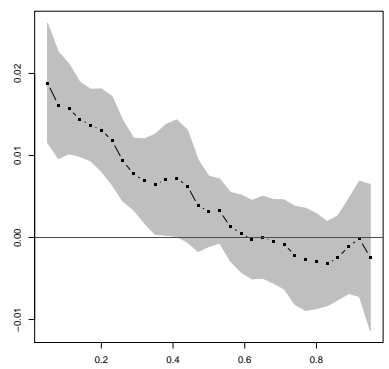

(i) $\mathrm{D} / \mathrm{P}$

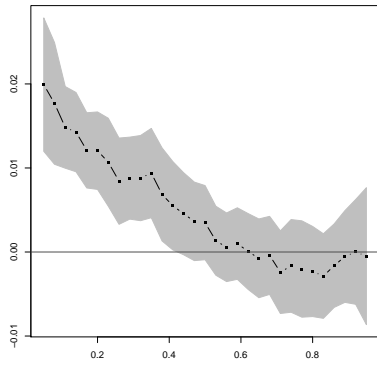

(b) $\mathrm{TB}$

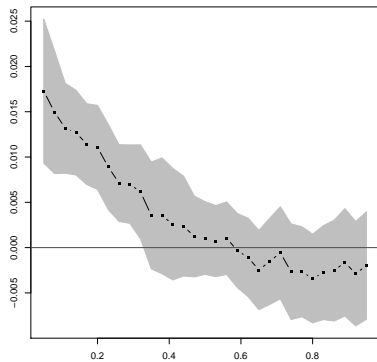

(f) LTR

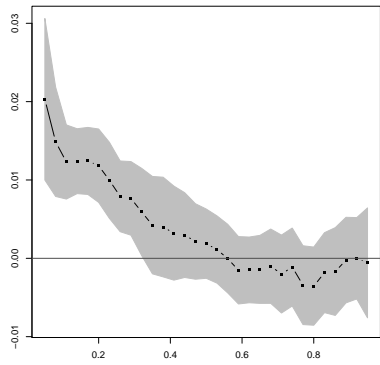

(j) $\mathrm{D} / \mathrm{E}$

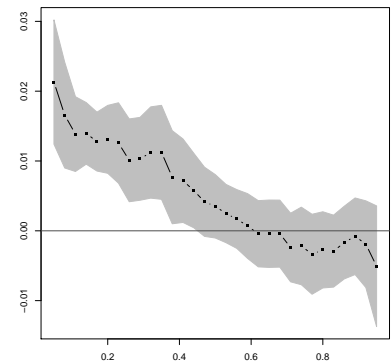

(c) LTY

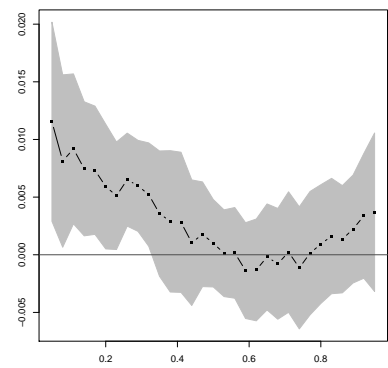

(g) $\mathrm{SV}$

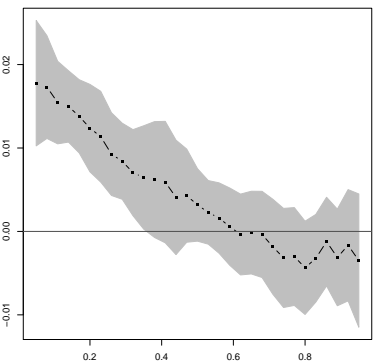

(k) E/P

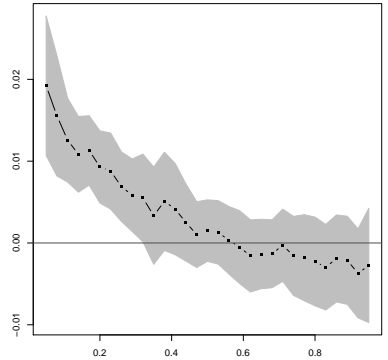

(d) NEE

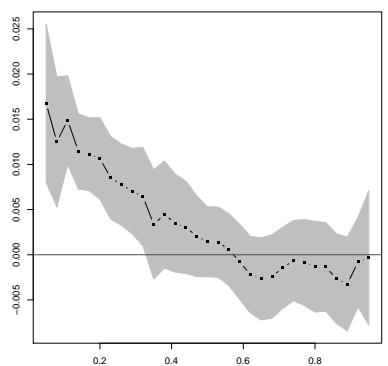

(h) DYS

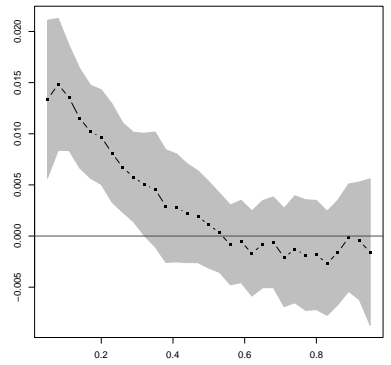

(l) $\mathrm{TS}$ 


\section{Figure 4}

\section{Bivariate Quantile Process Estimates (S\&P 500)}

This figure shows plots of the quantile process estimates of the slope parameter on tail risk $\beta_{\tau}$ for Eq. (7) where $\tau=0.05,0.08,0.11, \ldots, 0.95$ and $h=1$. The dependent variable is the S\&P 500 index return. Each plot depicts the quantile process estimate for the tail risk parameter when an alternative predictor, as shown in the caption under the plot, is included in the model as an additional regressor. The $90 \%$ confidence intervals are depicted by the shade areas in the plots.

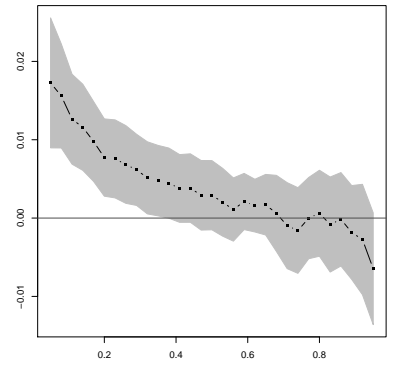

(a) $\mathrm{B} / \mathrm{M}$

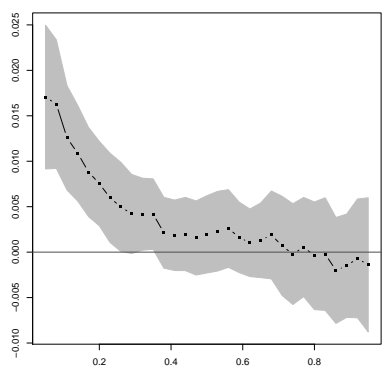

(e) INF

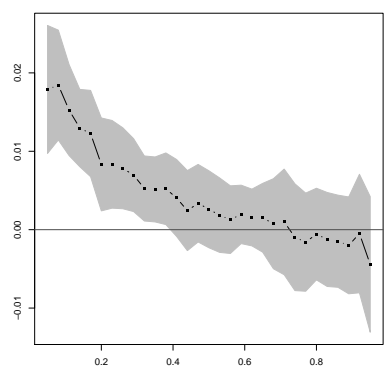

(i) $\mathrm{D} / \mathrm{P}$

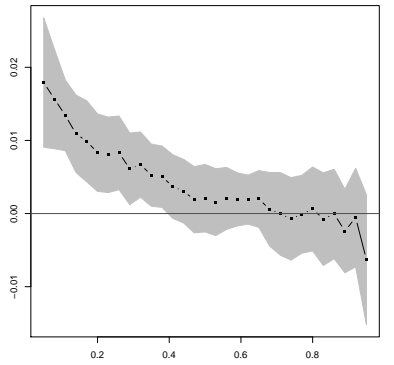

(b) $\mathrm{TB}$

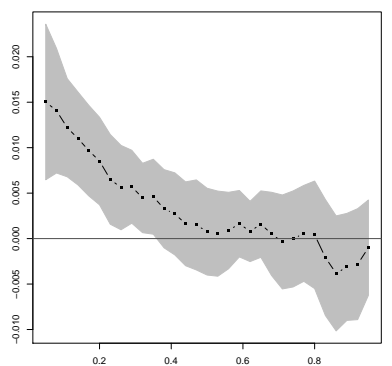

(f) LTR

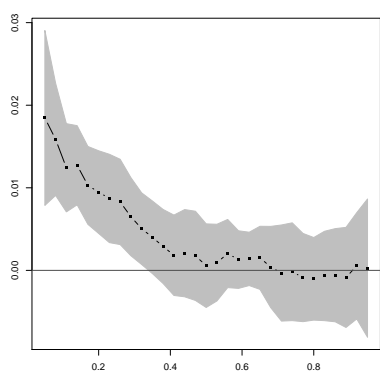

(j) $\mathrm{D} / \mathrm{E}$

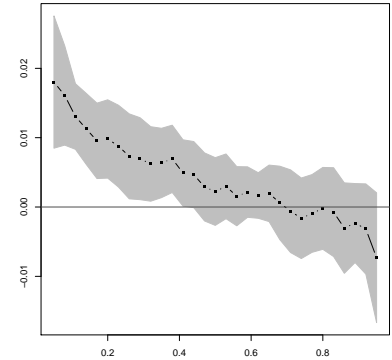

(c) LTY

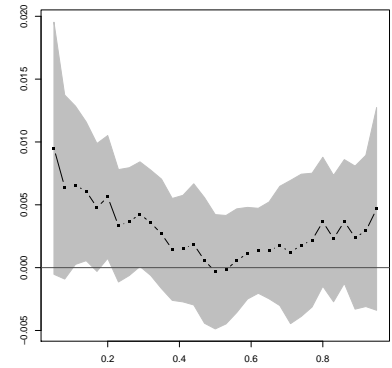

(g) $\mathrm{SV}$

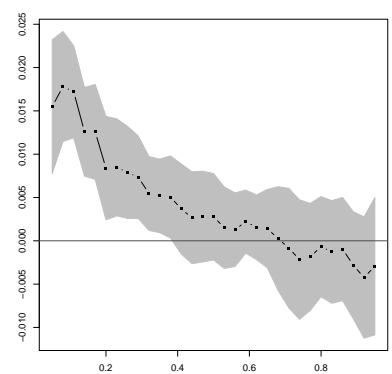

(k) E/P

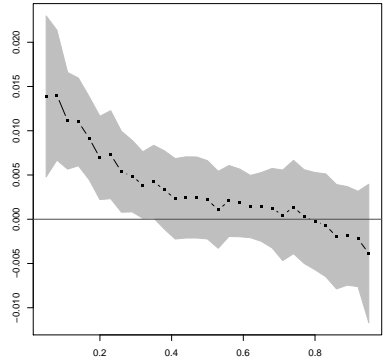

(d) NEE

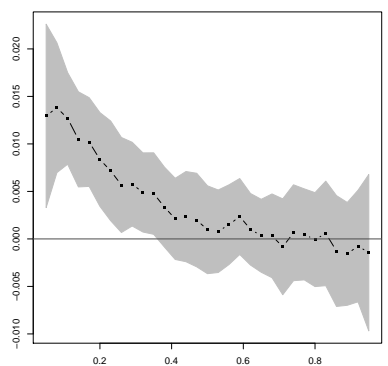

(h) DYS

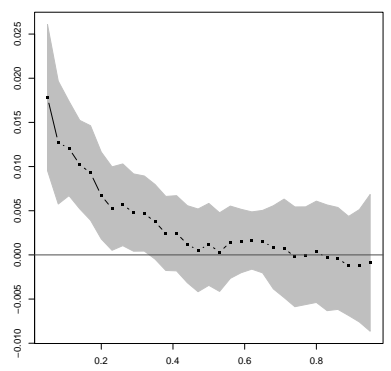

(l) $\mathrm{TS}$ 